\title{
Dynamics of Lithium Insertion in Electrochromic Titanium Dioxide Nanocrystal Ensembles
}

\author{
Clayton J. Dahlman, ${ }^{\dagger}, \S$ Sungyeon Heo,${ }^{\S}$ Youtian Zhang,${ }^{\dagger}$ Lauren C. Reimnitz,${ }^{\S}$

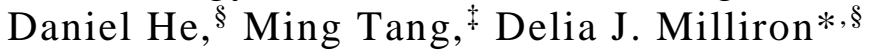 \\ ${ }^{\dagger}$ Materials Department, University of California, Santa Barbara, California 93106, U. S. A.
}

${ }^{\S}$ McKetta Department of Chemical Engineering, The University of Texas at Austin, Austin, Texas 78712, United States;

$\$$ Department of Materials Science and Nanoengineering, Rice University, 6100 Main Street, Houston, Texas 77005, United States

*Corresponding Author: milliron@che.utexas.edu

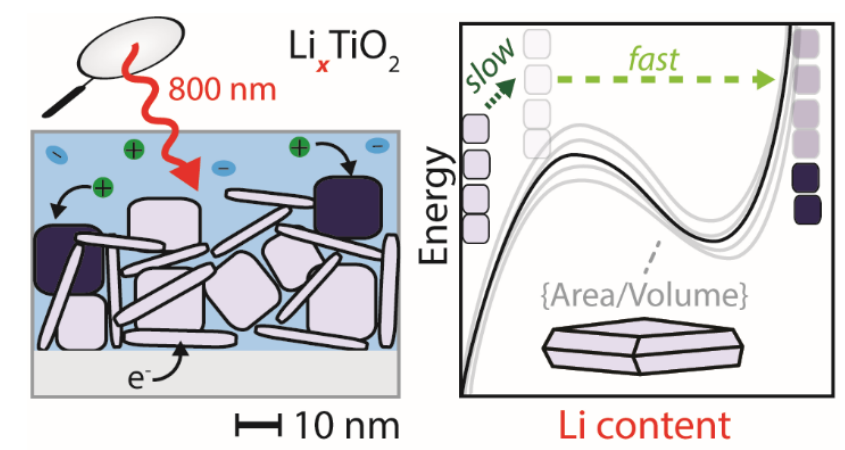

\section{Abstract:}

Nanocrystalline anatase $\mathrm{TiO}_{2}$ is a robust model anode for Li-insertion in batteries. The influence of nanocrystal size on the equilibrium potential and kinetics of Li-insertion is investigated with in operando spectroelectrochemistry of thin film electrodes. Distinct visible and infrared responses correlate with Li-insertion and electron accumulation, respectively, and these optical signals are used to deconvolute $\mathrm{Li}$-insertion from other electrochemical responses, such as double-layer capacitance and electrolyte leakage. Electrochemical titration and phase-field simulations reveal that a difference in surface energies between anatase and lithiated phases of $\mathrm{TiO}_{2}$ systematically tunes Li-insertion potentials with particle size. However, particle size does not affect the kinetics of Li-insertion in ensemble electrodes. Rather, Li-insertion rates depend on applied overpotential, electrolyte concentration, and initial state-of-charge. We conclude that Li diffusivity and phase propagation are not rate-limiting during $\mathrm{Li}$-insertion in $\mathrm{TiO}_{2}$ nanocrystals. Both of these processes occur rapidly once the transformation between the low-Li anatase and high-Li orthorhombic phases begins in a particle. Instead, discontinuous kinetics of $\mathrm{Li}$ accumulation in $\mathrm{TiO}_{2}$ particles prior to the phase transformations limits (dis)charging rates. We demonstrate a practical means to deconvolute non-equilibrium charging behavior in nanocrystalline electrodes through a combination of colloidal synthesis, phase field simulations and spectroelectrochemistry.

Keywords: Nanocrystal, ion insertion, $\mathrm{TiO}_{2}$, electrochromism, phase field simulations, battery 


\section{Introduction}

Li-ion batteries are commercially important because of their high volumetric and gravimetric capacities, along with high cycle stability at room temperature. ${ }^{1-3}$ Typical electrode materials in current-generation commercial Li-ion batteries, namely graphitic anodes and lithiumtransition metal oxide cathodes, store and release charge through reversible continuous or discontinuous Li insertion and extraction reactions with the host structure. ${ }^{1,2,4,5}$ High power density and rapid charging rates are concerns for many applications (e.g. transportation), so great efforts have been made to understand and improve the kinetics of these Li-insertion reactions. Nanostructured anatase $\mathrm{TiO}_{2}$ is a candidate $\mathrm{Li}$-ion anode with moderate specific capacity and excellent cycle stability at (dis)charging rates relevant to transportation applications. ${ }^{6-14}$ The rate at which battery electrodes, including nanostructured anatase, can be reliably charged and discharged depends on the kinetics of charging processes, including surface capacitance, phase transformations due to $\mathrm{Li}$-ion intercalation, and conversion reactions. ${ }^{15-17}$ An assortment of in situ and in operando characterization tools have been developed to observe these processes, and inform developments in mesoscale architecture, electrode particle morphology, composition and surface chemistry of mature and frontier electrode materials. ${ }^{18-22}$ However, in operando characterization of electrochemical transformations is often limited by a trade-off between time and length resolution, or instrumentation costs. Here, we demonstrate how optical characterization of electrodes, composed of electrochromic colloidal $\mathrm{TiO}_{2}$ nanocrystals with precisely controlled morphology, can deconvolute Li-insertion phase transformations through convenient and accessible techniques. We find that particle size systematically tunes the potentials of two-phase (de)lithiation reactions in nanocrystalline $\mathrm{TiO}_{2}$, and we justify these results through phase-field models that account for particle surface energy. We discover through transient measurements of nanocrystal electrodes and single-particle simulations that slow Li diffusivity or phase boundary propagation rates do not inherently limit charging kinetics. Rather, at potentials near the two-phase coexistence plateau, slow $\mathrm{Li}$ accumulation in particles before the onset of the phase transformation serves as an effective nucleation barrier to (de)lithiation reactions. These results demonstrate how polydispersity and discontinuous phase transformations within $\mathrm{TiO}_{2}$ nanocrystal ensembles impact charging rates in electrodes at different states of charge.

Titania and lithium titanate polymorphs, including spinel $\mathrm{Li}_{4} \mathrm{Ti}_{5} \mathrm{O}_{12},{ }^{23-28}$ anatase, ${ }^{6-12} \mathrm{TiO}_{2-}$ B bronze ${ }^{29-33}$ and amorphous phases, ${ }^{34-37}$ are prototypical Li-ion anodes that charge through lithium insertion and surface reactions in nanostructured electrodes. In particular, anatase $\mathrm{TiO}_{2}$ has charge storage densities competitive with conventional graphite electrodes and a small volume change during Li-ion insertion that allows for high cycle and calendar lifetimes at fast charging rates. ${ }^{6-14}$ However, the broad use of titanium oxide anodes is limited by their relatively high potentials (i.e., low specific energy), slow lithium diffusion and low intrinsic electronic conductivity. Despite these issues, titanium oxide phases have been explored as alternative anode materials in certain battery applications because of their low cost and durability at high cycle rates. $^{38-44}$

Charge storage in Li-ion batteries, including $\mathrm{TiO}_{2}$ anodes, can occur through different structural mechanisms depending on the intrinsic and extrinsic properties of the electrode. Li ions can be incorporated into the electrode host lattice, through insertion charging, or at electrode 
interfaces through double-layer capacitive or pseudo-capacitive mechanisms. Battery performance depends on the convoluted rates, pathways, and total charge capacities of each of these mechanisms during cycling, yet distinguishing these different contributions during charging remains a major challenge. ${ }^{15,19,20,45,46}$

During insertion charge storage processes, $\mathrm{Li}$ inserts into (or out of) the host electrode through either a single-phase reaction or across a first-order phase transition (i.e., a discontinuous transition between two distinct phases). For a single-phase process the host material transforms continuously with $\mathrm{Li}$ content (e.g., $\mathrm{Li}_{x} \mathrm{Ni}_{1 / 3} \mathrm{Mn}_{1 / 3} \mathrm{Co}_{1 / 3} \mathrm{O}_{x}$ ), while first-order phase transitions occur across a miscibility gap between Li-ion stoichiometries (e.g., $\mathrm{Li}_{x} \mathrm{FePO}_{4}$ and anatase $\left.\mathrm{TiO}_{2}\right){ }^{5,9,47} \mathrm{The}$ balance of single-phase and two-phase processes depends on the crystal structure of the electrode and can change with the rate of charging or grain size. ${ }^{8,9,48-57}$ Across the entire potential range during cycling a mixture of single-phase and two-phase charge storage reactions often occur. For instance, anatase $\mathrm{TiO}_{2}$ undergoes a two-phase reaction around $1.8 \mathrm{~V}$ vs. $\mathrm{Li} / \mathrm{Li}^{+}$, with significant changes in the unit cell, Li-ion diffusivity, and electronic conductivity, whereas at voltages above and below this potential (before the onset of a separate two-phase transformation below $1.5 \mathrm{~V}$ ) the host structure transforms continuously with Li content. ${ }^{6-8,58-63}$ Although two-phase insertion reactions can store large charge capacities over long calendar and cycle lifetimes, their charging kinetics are often slower than single-phase or surface reactions due to activation energy barriers, and can be limiting for high-rate applications. ${ }^{9}$ Much effort has been devoted to either increase the rate of two-phase reactions, or to favor faster one-phase reactions for high-rate batteries.

Capacitive surface charging can also contribute significant high-rate capacity in nanostructured electrodes. ${ }^{15,46,64,65}$ Electrochemical capacitors, and materials with large interstitial sites or intrinsically high internal surface area, are useful for ultra-fast charging or applications that require high power density. ${ }^{2}$ Double-layer capacitance, 'pseudo-capacitance' and insertion charge storage processes can all happen simultaneously in nanostructured electrodes, and are difficulty to distinguish by electrochemical means alone. ${ }^{15,16}$ For instance, in nanocrystalline films of anatase $\mathrm{TiO}_{2}$, with particles smaller than $10 \mathrm{~nm}$, about half of the electrode charge capacity is attributed to 'pseudo-capacitive' processes, ${ }^{65}$ with surface-limited charging kinetics. ${ }^{66,67}$ Capacitive processes occur continuously with Li content and can be convoluted with single-phase $\mathrm{Li}$ insertion as well. In addition to enabling capacitive charging, nanostructuring also mitigates challenges of low diffusivity and conductivity in electrode particles by reducing charge transport path lengths. ${ }^{68}$ The grain morphology of nanocrystalline $\mathrm{TiO}_{2}$ can thus have a two-fold impact on battery performance, both by changing the rates and pathways of Li-insertion reactions, and by contributing to surface charge storage.

Surfactant-mediated colloidal synthesis provides a well-controlled route to manipulate grain morphologies in $\mathrm{TiO}_{2}$ nanocrystals for nanostructured electrodes. The size and shape of electrode nanocrystals, including anatase $\mathrm{TiO}_{2}$, can be tuned by changing conditions during colloidal synthesis, while polydispersity can be narrowed via size-selective precipitation. ${ }^{69-72}$ The surface chemistry of electrode nanomaterials such as $\mathrm{TiO}_{2}$ is also tunable, ${ }^{73}$ either during synthesis, within dispersions, or after deposition, by mass-action ligand exchange ${ }^{74}$ or ligand-substituting reactions. ${ }^{75,76}$ There are distinct practical challenges that offset the versatility of colloidal nanomaterials in batteries, ${ }^{77-79}$ but anodes with high specific capacity and cycle stability at 
practical charging rates have nevertheless been formed from monodisperse colloids of $\mathrm{TiO}_{2}$, even without conductive binder additives. ${ }^{80,81}$ Thus, colloidal nanocrystal synthesis provides a practical means to design electrode films and test the effects of microstructure on charging properties.

Optical indicators can deconvolute different electrochemical transformations in nanocrystalline $\mathrm{TiO}_{2}$ at a time resolution relevant to fast charging processes. Surface charging or continuous single-phase reactions (i.e., without any change in crystalline symmetry) reduce anatase $\mathrm{TiO}_{2}$ to an electronically degenerate state, inducing broad Drude absorption in the infrared ${ }^{82}$ Upon lithium insertion and conversion to orthorhombic $\mathrm{Li}_{\sim} 0.5 \mathrm{TiO}_{2}$, a polaronic absorption feature arises in the visible that induces a deep blue color ${ }^{83-87}$ These two coloration mechanisms are distinct and can be analyzed independently through UV, visible, and near-IR transmittance measurements. ${ }^{87}$ In situ optical measurements through thin-films have temporal and spatial resolution limited only by the optics, detector, and electronics of the spectrometer. The main constraint is the transparency of the electrode and substrate. Thin electrodes must be deposited on transparent conductive current collectors (e.g., glass coated with tin-doped indium oxide) and charged within an in operando half-cell apparatus. Transmittance measurements of

electrodes with an electrochromic response (e.g., graphite, ${ }^{88} \mathrm{Li}_{4} \mathrm{Ti}_{5} \mathrm{O}_{12},{ }^{89} \mathrm{Li}_{x} \mathrm{FePO}_{4},{ }^{90}$ and $\mathrm{Li}_{\mathrm{x}} \mathrm{CoO}_{2},{ }^{91}$ and $\mathrm{Nb}_{2} \mathrm{O}_{5}{ }^{92}$ ) are a powerful technique to measure distinct charging processes, without convoluting signals from leakage current, at the time-scales of practical battery operation. The present work uses in operando optical spectroscopy of $\mathrm{TiO}_{2}$ nanocrystal films during $\mathrm{Li}$-ion charging, coupled with simulations of charging at the single-particle and ensemble scales, to examine how particle morphology and ensemble interactions impact behavior at equilibrium and during dynamic charging.

\section{Experimental}

See the Supporting Information.

\section{Results and Discussion}

\section{Synthesis of size-controlled $\mathrm{TiO}_{2}$ nanocrystals}

Anatase $\mathrm{TiO}_{2}$ is a metastable polymorph that is typically observed in particles smaller than $100 \mathrm{~nm}$ due to the low surface energy of anatase relative to other stable phases. ${ }^{93}$ Many synthetic techniques have been used to make nanocrystalline anatase $\mathrm{TiO}_{2}$ electrodes with a wide range of particle sizes and shapes, yielding a corresponding variety of electrochemical properties. Differences in specific capacity, cycle stability, and energy density have been attributed to the faceting, size, and mesostructure of nanostructured $\mathrm{TiO}_{2}$ electrodes. ${ }^{10,41,44}$ However, polydispersity among nanocrystal ensembles can obscure the precise relationship between nanoparticle structure and electrode behavior. Surfactant-mediated colloidal synthesis provides an effective method to 
control the morphology of $\mathrm{TiO}_{2}$ nanocrystals while limiting polydispersity in the particle ensemble. $^{71,72}$

The size and shape of colloidal anatase $\mathrm{TiO}_{2}$ nanocrystals can be controlled by varying the composition of growth precursors. The minimum energy configuration of anatase $\mathrm{TiO}_{2}$ is a square bipyramidal structure with exposed $\{101\}$ facets. ${ }^{94}$ However, in a colloidal nucleation and growth synthesis, metastable particle shapes can form by tuning the kinetic growth rates at each facet. ${ }^{71,72,95-97}$ Strong binding of fluoride produced during the decomposition of a $\mathrm{TiF}_{4}$ precursor is found to stabilize the $\{001\}$ facet and change the shape of $\mathrm{TiO}_{2}$ nanocrystals, without incorporating in the nanocrystal as a dopant. ${ }^{98}$ The presence of an amine such as oleylamine (OLAM) sequesters fluoride ions and prevents them from stabilizing the $\{001\}$ facets, thus providing a mechanism to tune the size and shape of monodisperse anatase nanocrystals. ${ }^{98}$ This synthesis yields either truncated bipyramidal nanocrystals - similar to the Wulff construction - if OLAM is used as a cosurfactant, or high aspect-ratio nanoplatelets with exposed $\{001\}$ facets if oleyl alcohol (OLAL) is used instead. Fluoride ions also induce oxygen vacancies in anatase nanocrystals during synthesis, which are compensated by free electrons. ${ }^{98}$ As a result, $\mathrm{TiO}_{2}$ nanocrystals prepared from $\mathrm{TiF}_{4}$ precursors show mid-infrared absorption characteristic of localized surface plasmon resonance. ${ }^{82,98,99}$ Enriching the oxygen vacancy content of $\mathrm{TiO}_{2}$ nanocrystals with $\mathrm{TiF}_{4}$ precursors provides the added benefit of improved electronic conductivity during charging.

Continuous variations in precursor stoichiometry yield tunable $\mathrm{TiO}_{2}$ nanocrystal morphology. Gordon et al described nanocrystal shapes at the extreme limits of cosurfactant ratios within an oleic acid-mediated chemothermal synthesis. ${ }^{98}$ However, finer variations in the ratio of OLAM and OLAL during synthesis with $\mathrm{TiF}_{4}$ precursor yield particles of intermediate size. Different ratios of OLAM:OLAL were added in a slow-injection synthesis to produce oxygendeficient nanoplatelets ranging in size from $4 \times 18 \times 18 \mathrm{~nm}$ to $7 \times 54 \times 54 \mathrm{~nm}$. Scanning transmission electron microscopy (STEM) images in Figure 1 demonstrate the range of particle sizes and morphologies synthesized in this manner, along with particle sizing histograms obtained by image analysis. Additional STEM images are shown in Figure S1, and details of the particle size distributions are provided in Table S1. Anisotropy in the size and shape of the particles was confirmed by XRD patterns for films of each particle through Scherrer analysis of different diffraction peaks (Figure 1b), as described in the Supporting Information (Figure S2).

To confirm the faceting of the nanoplatelets, high-resolution transmission electron microscopy (HR-TEM) was performed on the largest nanoplatelet sample synthesized with OLAL-only cosurfactant. Figure 1d shows a low-magnification survey image of the $7 \times 54 \mathrm{~nm}$ nanoplatelets synthesized with the OLAL co-surfactant. The platelets appear to be square, and they tend to cluster at random angles to the substrate. Figure 1d shows high-resolution imaging of a platelet laying with a square projection in the electron beam. Fourier transform of selected areas in the image reveal a persistent peak at $2.81 \mathrm{~nm}^{-1}$, which corresponds to intensity with a periodicity of $3.56 \AA$. This corresponds well to the $\{101\}$ plane spacing of $3.51 \AA$, albeit with an expansion of $1.4 \%$ strain perpendicular to the $\{101\}$ planes. The exposed edges of the nanoplatelets are therefore perpendicular members of the $\{100\}$ family of planes, as expected from prior studies. ${ }^{98}$ 

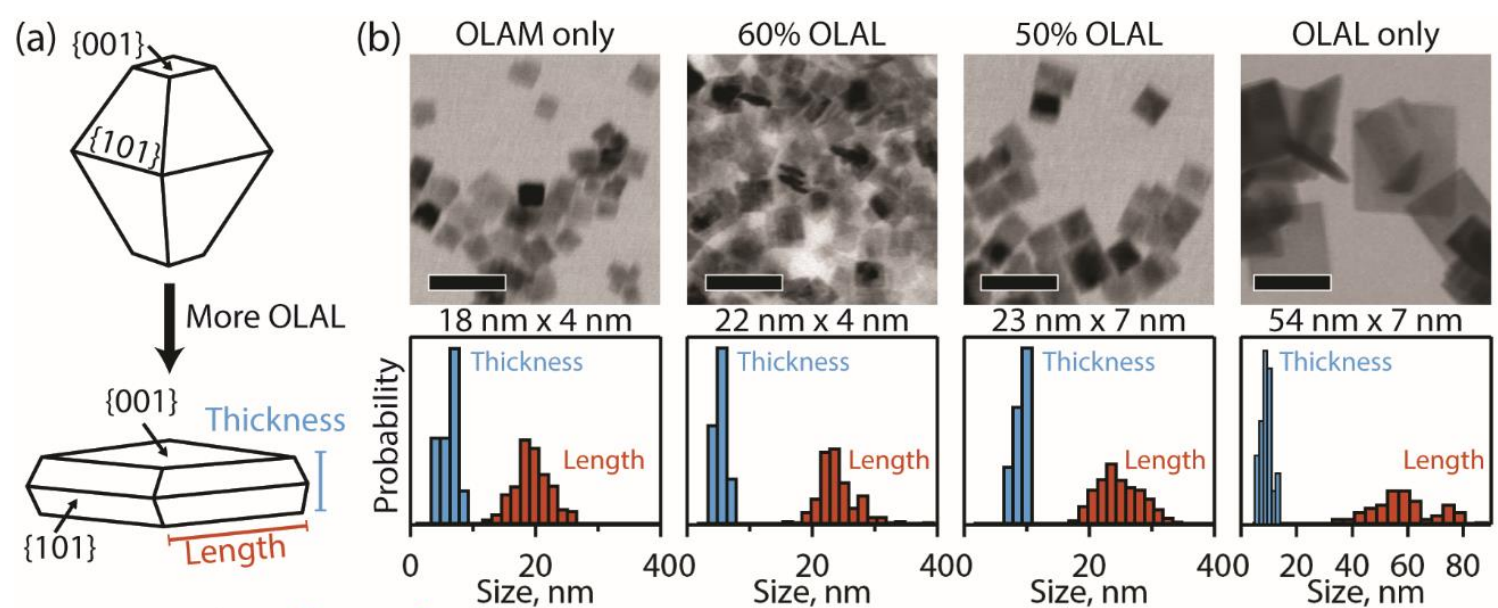

$54 \mathrm{~nm} \times 7 \mathrm{~nm}$

(c)

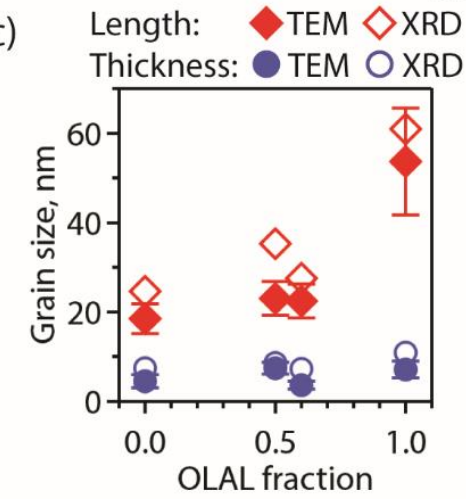

(d)

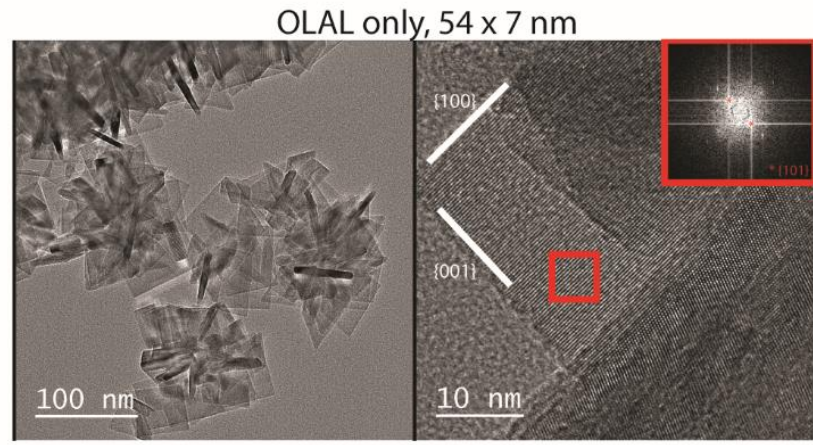

Figure 1. a) A schematic of $\mathrm{TiO}_{2}$ particle morphologies prepared with either oleylamine (OLAM) or oleyl alcohol (OLAL) co-surfactants. b) STEM images of $\mathrm{TiO}_{2}$ nanoplatelets synthesized with different ratios of OLAM and OLAL co-surfactants in the precursor. The scale bar is $50 \mathrm{~nm}$. Histograms of particle sizes were measured by analysis of STEM images. Red histogram bars show measured particle length, and blue histogram bars show measured thickness. c) A comparison of the length and thickness dimensions of the nanoplatelet samples shown in a), estimated from STEM sizing and Scherrer broadening of deposited film powder X-ray diffraction peaks. d) High-resolution TEM images of OLAL-only nanoplatelets taken at low and high magnification.

\section{Deconvoluting Li-insertion phase transformations in $\mathrm{TiO}_{2}$}

Thin film electrodes were prepared from each nanocrystal sample to compare charging capacity and rates between nanocrystals with different morphologies. Nanocrystals were deposited from dispersions by spin-coating on conductive glass slides and ligand-exchanged to displace the bulky insulating native ligands, yielding films with thickness ranging from 100-200 nm (Table S2). Nanocrystal films were used as electrodes with a non-aqueous $0.1 \mathrm{M} \mathrm{LiTFSI}$ in tetraglyme electrolyte, and charged in a half cell geometry with a Li foil counter-electrode. We did not add a conductive binder because electron and ion transport path-lengths across the thin film are very short, as observed in electrochromic window coatings prepared by similar processes. ${ }^{87,100,101}$ 
Nanocrystalline $\mathrm{TiO}_{2}$ films store charge through a combination of single-phase and twophase lithium insertion reactions and non-Faradaic processes. In bulk anatase $\mathrm{TiO}_{2}$, the lattice reversibly incorporates up to $2 \mathrm{Li}$ per unit cell ( $1 \mathrm{Li}$ per $\mathrm{TiO}_{2}$ formula unit) in open interstitial voids through a series of single-phase and two-phase electrochemical reactions. At potentials above 1.8 $\mathrm{V}$ lithium inserts in the tetragonal phase up to a stoichiometry of about $\mathrm{Li} 0.2 \mathrm{TiO}_{2}$ through a singlephase reaction. A phase transition between anatase $\mathrm{Li}_{\sim 0.2} \mathrm{TiO}_{2}\left(\mathrm{I} 41 / \mathrm{amd}\right.$, ICSD Coll. Code 96947) ${ }^{58}$ and orthorhombic $\mathrm{Li} \sim 0.5 \mathrm{TiO}_{2}$ (Imma, ICSD Coll. Code 36449$)^{14}$ occurs around $1.75 \mathrm{~V}$ vs. $\mathrm{Li}^{1} / \mathrm{Li}^{+}$. 6,7 At more reducing potentials $(<1.4 \mathrm{~V})$ a secondary two-phase transition can occur, from orthorhombic $\mathrm{Li} \sim 0.5 \mathrm{TiO}_{2}$ to tetragonal $\mathrm{Li}_{1} \mathrm{TiO}_{2}$ (I41/amd, ICSD Coll. Code 164158) $)^{8,102}$. However, this transition occurs more slowly than the anatase to orthorhombic $\mathrm{Li}_{\sim 0.5} \mathrm{TiO}_{2}$ two-phase reaction and has limited electrochemical cyclability. ${ }^{9,53,102}$ Nanostructured $\mathrm{TiO}_{2}$ films also store charge through non-Faradaic surface charging processes, ${ }^{15}$ with important, albeit convoluted, effects on battery capacity and charging rates.

The capacity of each film was estimated by cyclic voltammetry (CV). CV measurements were performed at a scan rate of $0.5 \mathrm{mV} / \mathrm{s}$ across a potential range of 3.5 to $1.5 \mathrm{~V} \mathrm{vs} \mathrm{Li} / \mathrm{Li}^{+}$. Measured capacities ranged from $10-40 \mathrm{mC}$, equivalent to about $400-500 \mathrm{mAh} / \mathrm{cm}^{3}$ (Figure S3). Capacities measured by $\mathrm{CV}$ were consistent with galvanostatic capacities measured at $\mathrm{C} / 1$ or $\mathrm{C} / 2$ rates (Figure S4), as well as previously reported values for nanostructured anatase $\mathrm{TiO}_{2}$ electrodes. ${ }^{10}$ A nanocrystal volume fraction of $80 \%$ was assumed (i.e., $20 \%$ void space), yielding gravimetric specific capacities ranging from 110 - $180 \mathrm{mAh} / \mathrm{g}$ across all samples, estimated based on the area and measured thickness for each film (Table S2). It is unclear if particle morphology has a systematic effect on specific capacity because of variations in film thickness and porosity. Note that the potential range used in these studies targets the tetragonal $\mathrm{TiO}_{2}$ to orthorhombic $\mathrm{Li} \sim 0.5 \mathrm{TiO}_{2}$ transition (along with any single-phase or pseudo-capacitive charging ${ }^{15}$ ), and does not access the significant capacity of the $\mathrm{Li} \sim 0.5 \mathrm{TiO}_{2}$ to $\mathrm{Li}_{1} \mathrm{TiO}_{2}$ transition. ${ }^{8,9,53,102}$ All nanocrystal samples were found to retain their capacity after several cycles (Figure S3).

To isolate the two-phase $\mathrm{Li}$ insertion reaction from single-phase and non-Faradaic processes, we performed electrochemical titration measurements. During two-phase transformations a large amount of charge is exchanged near a particular potential (i.e., the critical potential for the transformation). Single-phase or surface charging processes, on the other hand, occur across a continuous range of potentials. Plateaus observed during galvanostatic charging of nanocrystal films indicate that roughly half of total capacity is due to the tetragonal $\mathrm{Li} \sim 0.2 \mathrm{TiO}_{2}$ to orthorhombic $\mathrm{Li}_{\sim 0.5} \mathrm{TiO}_{2}$ transition (Figure S4). We note that the potential in this experiment did not reach the threshold for the secondary two-phase transformation to tetragonal $\mathrm{LiTiO}_{2}$. The precise potential of the $\mathrm{Li} \sim 0.2 \mathrm{TiO}_{2}$ to $\mathrm{Li}_{\sim 0.5} \mathrm{TiO}_{2}$ two-phase reaction, upon both oxidation and reduction, can be measured with electrochemical titrations, including the galvanostatic intermittent titration technique (GITT) and potentiostatic intermittent titration technique (PITT). We employed PITT and GITT to compare the critical potentials of two-phase insertion reactions between $\mathrm{TiO}_{2}$ nanocrystal films with different particle morphologies.

PITT measurements reveal the critical potentials of the two-phase lithiation reaction in nanocrystalline $\mathrm{TiO}_{2}$ films. During each charge titration step in the PITT experiment, the potential was held constant until the current declined to a pre-determined value (a current of $\mathrm{C} / 25$ defined 
by prior CV experiments, Figure S3). Figure 2a shows the full PITT experiment for $7 \times 23 \mathrm{~nm}$ $\mathrm{TiO}_{2}$ nanoplatelet films (50\% OLAM, Figure 1). The integrated charge accumulated for each $5 \mathrm{mV}$ step is shown as a function of potential in Figure 2d. Only a small amount of charge is accumulated during each step (Figure 2d), except for clear peaks that indicate the two-phase reactions for lithiation $(1.770 \mathrm{~V})$ or delithiation $(1.830 \mathrm{~V})$. Step-wise capacity increases at potentials below $1.6 \mathrm{~V}$ upon lithiation, which may be caused by electrolyte side reactions or the sluggish two-phase reaction from orthorhombic $\mathrm{Li}_{\sim} 0.5 \mathrm{TiO}_{2}$ to tetragonal $\mathrm{Li}_{1} \mathrm{TiO}_{2} .{ }^{9}, 53,102$ Indeed, a shallow feature around $1.7 \mathrm{~V}$ upon delithiation implies that some orthorhombic $\mathrm{Li}_{\sim} 0.5 \mathrm{TiO}_{2}$ converts to tetragonal $\mathrm{Li}_{1} \mathrm{TiO}_{2}$ upon reduction, and returns to orthorhombic $\mathrm{Li}_{\sim} 0.5 \mathrm{TiO}_{2}$ upon oxidation (Figure S9c).

GITT measurements also identify the critical potentials of two-phase lithiation, but nucleation barriers to lithium insertion in $\mathrm{TiO}_{2}$ nanocrystals obscure the results. GITT measures equilibrium transformation potentials by observing how potential responds to discrete galvanostatic charging steps upon relaxation, thereby eliminating kinetic effects. ${ }^{21,103}$ GITT measurements of $7 \times 23 \mathrm{~nm} \mathrm{TiO}_{2}$ nanoplatelet films (50\% OLAM, Figure 1) are shown in Figure S5. Sharp plateaus in step-wise capacity $(\Delta \mathrm{Q} / \Delta \mathrm{V})$ are observed at $1.791 \mathrm{~V}$ and $1.832 \mathrm{~V}$ for lithiation and delithiation, respectively, and can be attributed to discontinuous two-phase insertion reactions (Figure S5a,b). However, GITT obscures the important role of nucleation barriers during two-phase reactions in nanostructured electrodes because large polarizations $(>100 \mathrm{mV})$ are applied during each galvanostatic charging step (Figure S5a,b). These nucleation barriers can have significant impacts on battery performance and charging hysteresis, ${ }^{104-106}$ and are not probed with great precision during GITT. Figure S5c compares how step-wise capacity changes with potential between PITT and GITT methods: the critical potential for lithiation is $20 \mathrm{mV}$ lower in the PITT experiment, reflecting the nucleation barrier to two-phase lithiation in these films. Particle morphology can impact both nucleation barriers and equilibrium phase transformation energetics ${ }^{54}$ so we rely on potentiostatic measurements (PITT) to compare the energetics of nanocrystalline $\mathrm{TiO}_{2}$ films.
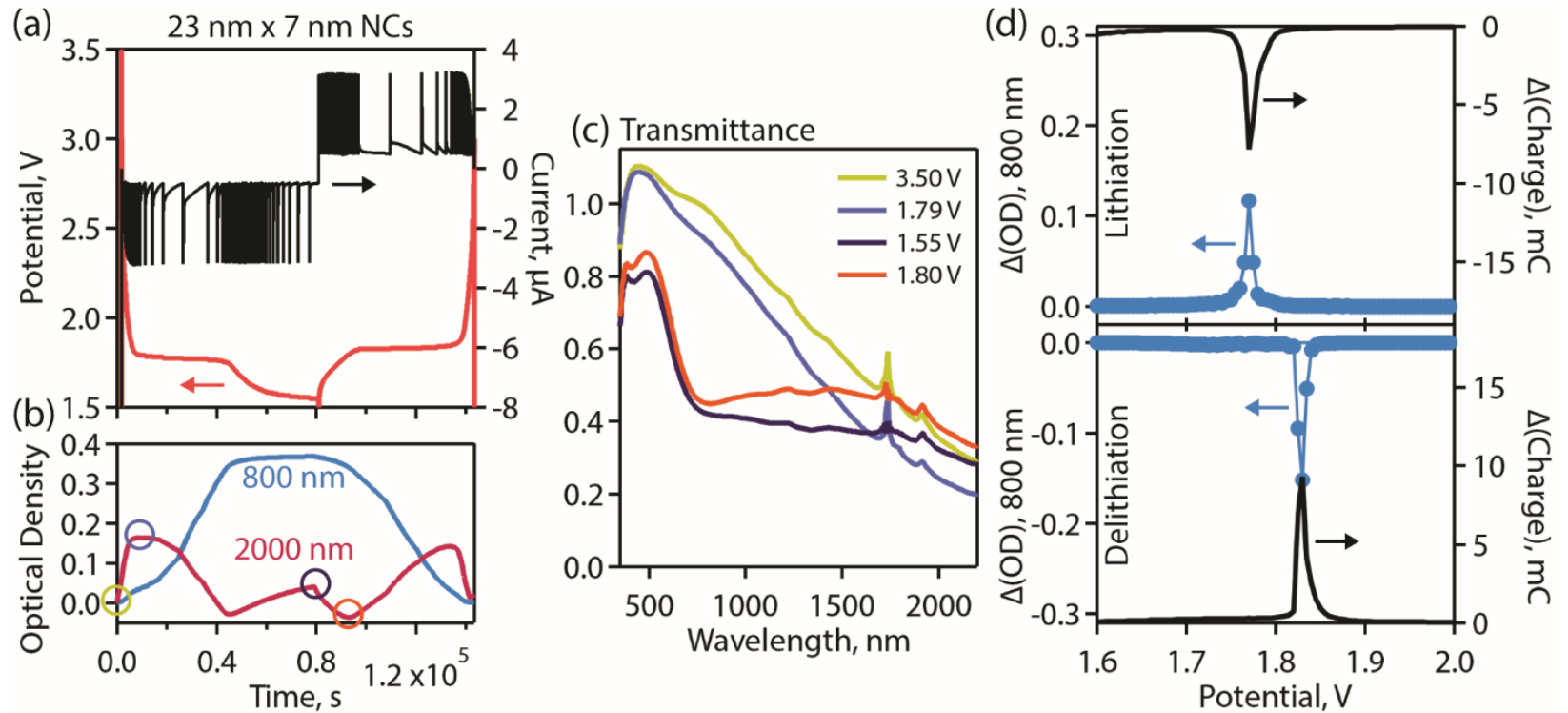
Figure 2. Potentiostatic intermittant titration technique (PITT) electrochemical measurements of a 50\% OLAL-synthesized $\mathrm{TiO}_{2}$ nanocrystal film. a) Measurements of current and potential during a $5 \mathrm{mV}$ step PITT experiment with a $\mathrm{C} / 25$ current threshold. b) A plot of optical density at $800 \mathrm{~nm}$ and $2000 \mathrm{~nm} v$ s. time, referenced to the time resolved potential measured during the PITT experiment. c) Optical transmittance spectra taken during the PITT experiment at different points during lithiation. The spectra correspond to time-points indicated by the markers in (b) of the same color. d) Integrated differential capacity across each potentiostatic charging step for the PITT measurement, along with integrated changes in optical density at $800 \mathrm{~nm}$ for the lithiation and delithiation reactions.

Anatase $\mathrm{TiO}_{2}$ presents an additional opportunity to isolate the two-phase insertion reaction because the transformation from the tetragonal to orthorhombic phase is accompanied by a visible coloration. This color change is attributed to polaronic gap states formed when electrons localize at $\mathrm{Ti}^{3+}$ sites near inserted lithium. ${ }^{84,86,107-109}$ Accumulated electrons are found to localize near inserted $\mathrm{Li}^{+}$in orthorhombic $\mathrm{Li}_{\sim} 0.5 \mathrm{TiO}_{2},{ }^{109}$ but it is unclear how these states interact in nanocrystals, or how localized states in tetragonal $\mathrm{Li}_{<0.2} \mathrm{TiO}_{2}$ contribute to visible coloration. Nonetheless, visible coloration effectively distinguishes the two-phase Li-insertion reaction from single-phase insertion and non-Faradaic charging. ${ }^{87}$

In situ measurements of film transmittance during PITT for a film of $7 \times 23 \mathrm{~nm}$ nanoplatelets are shown in Figure 2. Distinct optical modulations occur in the visible and infrared portions of the spectrum (Figure 2c), which can be attributed to the two-phase insertion reaction and single-phase/non-Faradaic charging, respectively. ${ }^{87}$ The $2000 \mathrm{~nm}$ feature is the high-energy tail of a localized resonant Drude response in conductive $\mathrm{TiO}_{2}$, and varies non-monotonically with potential. The $2000 \mathrm{~nm}$ feature can be used as an in situ probe of the optical conductivity of $\mathrm{TiO}_{2}$ nanocrystals in a film. ${ }^{82}$ Conversely, an optical density (OD) peak at $800 \mathrm{~nm}$ primarily increases across the two-phase potential plateau in the charging curve (Figure 2b). A comparison of the step-wise color change with step-wise charge capacity reveals that the two signals are highly correlated (Figure 2d). Moreover, optical coloration at $800 \mathrm{~nm}$ is specific to the two-phase insertion reaction, without convolutions from minor charging processes observed during PITT at potentials above and below the two-phase plateau (Figure S9c,f). Thus, the combination of PITT and optical transmission measurements at $800 \mathrm{~nm}$ can be used as a precise in operando probe of the two-phase anatase to orthorhombic transformation.

\section{Energetic effects of nanocrystal morphology on $\mathrm{Li}$ insertion}

Particle morphology shifts the critical overpotential of the two-phase lithiation reaction. Figure 3a compares the step-wise capacity and differential optical density measured during PITT experiments for different particle morphologies. Sharp peaks in step-wise charge accumulation and color change are observed around $1.8 \mathrm{~V}$ upon both lithiation and delithiation in all samples. Step-wise peak widths and potentials are identical between optical and electrochemical measurements. The potential of these peaks shifts with particle size. The largest particles $(54 \times 7$ $\mathrm{nm}$ ) have delithiation peaks at $1.840 \mathrm{~V}, 10 \mathrm{mV}$ more positive than any of the smaller particles at 
$1.830 \mathrm{~V}$. Upon lithiation, the largest particles have peaks at $1.790 \mathrm{~V}, 20 \mathrm{mV}$ more positive than the smaller particles at $1.770 \mathrm{~V}$. These peaks can be directly assigned to the two-phase tetragonal to orthorhombic transformation, and indicate that particle size or faceting affects the energetics of lithiation in anatase $\mathrm{TiO}_{2}$. The near-equilibrium conditions of the PITT experiment, and fine control of particle size and faceting through colloidal synthesis, allow this precise measurement of size-dependent lithiation energetics. Size effects in nanostructured Li-insertion electrodes are welldocumented for electrode capacity, charging rates and mechanisms (e.g. $\mathrm{Li}_{x} \mathrm{TiO}_{2}, 9,48,64,110,111$ $\mathrm{Li}_{x} \mathrm{FePO}_{4},{ }^{112}$ and $\mathrm{Li}_{x} \mathrm{CoO}_{2}{ }^{113,114}$ ) due to surface energetics, strain effects and kinetics. ${ }^{17}$ However, there is a scarcity of reported equilibrium charging experiments (e.g. PITT and GITT) with nanostructured Li-ion electrodes because most attention is directed towards behavior at practical charging rates for batteries. Notably, size-dependent shifts $(<100 \mathrm{mV})$ in equilibrium (de)lithiation potentials have been observed in nanocrystalline $\mathrm{Li}_{x} \mathrm{FePO}_{4}{ }^{112}$ and $\mathrm{Li}_{x} \mathrm{TiO}_{2}{ }^{48,111}$ electrodes, but synthetic polydispersity in particle size and faceting obscures the connection between particle morphology and energetics in these measurements.

The difference in critical overpotential of the two-phase lithiation reaction may be related to differences in surface energy between nanocrystals. Van der Ven and Wagemaker proposed a general theory that connects particle size to the equilibrium potential of two-phase lithiation reactions by accounting for the surface energy in small $(<100 \mathrm{~nm})$ nanocrystals. ${ }^{115}$ Surface energy contributes an additional term to the free energy, $F(x)$, of both the anatase $(\alpha)$ or lithiated $\mathrm{TiO}_{2}(\beta)$ phases for small particles:

$$
F_{\alpha, \beta}(x)=F_{b u l k, \alpha, \beta}(x)+\frac{A \Omega \gamma_{\alpha, \beta}}{V}
$$

Here, $x$ is the lithium concentration in the particle, $\Omega$ is the molar volume $\left(21 \mathrm{~cm}^{3} / \mathrm{mol}\right.$ for anatase $\mathrm{TiO}_{2}$ ), $A$ is the particle surface area and $V$ is the particle volume. The surface energy, $\gamma$, need not be equal between each phase, so the contribution from surface energy for anatase and lithiatied phases of the same particle can differ. ${ }^{115}$ As described in more detail in the Supporting Information, this difference in surface energy can introduce shifts in the transformation potential for particles of different sizes (Figure S10), but these small shifts in potential have been difficult to observe experimentally.

Decreasing particle size is correlated with more negative transformation potentials for both lithiation and delithiation reactions (Figure 3). This result implies that the surface energy of orthorhombic $\mathrm{Li} \sim 0.5 \mathrm{TiO}_{2}$ must be greater in magnitude than that of tetragonal $\mathrm{Li}<0.2 \mathrm{TiO}_{2}($ Figure S10). The extent of this difference in surface energy can be approximated by considering the size and shape of the different samples. $\mathrm{TiO}_{2}$ nanocrystals are idealized as rectangular prisms with width and thickness defined by the particle size distributions shown in Figure 1. Assuming equal surface energies for each facet, a $20 \mathrm{mV}$ difference in lithiation potential between the smallest (4 $\times 18 \mathrm{~nm})$ and largest $(7 \times 54 \mathrm{~nm})$ nanoplatelets corresponds to a surface energy difference of roughly $0.11 \mathrm{~J} / \mathrm{m}^{2}$ between the anatase and lithiated orthorhombic phases (Figure S10). This simple model neglects several details of the system, and the surface energies of each exposed facet may behave quite differently upon (de)lithiation. To our knowledge the surface energies of the orthorhombic $\mathrm{Li} \sim 0.5 \mathrm{TiO}_{2}$ phase have not been characterized, but studies of anatase $\mathrm{TiO}_{2}$ suggest 
surface energies ranging from $0.35-0.52 \mathrm{~J} / \mathrm{m}^{2}$ for the $\{101\}$ facet and $0.51-0.96 \mathrm{~J} / \mathrm{m}^{2}$ for the $\{001\}$ facet, ${ }^{94,116-118}$ and a similar range for average surface energies. ${ }^{119-121}$ Computations of the (111) surface of a comparable material, $\mathrm{Li}_{4} \mathrm{Ti}_{5} \mathrm{O}_{12}$, indicate that surface energies increase from $0.35 \mathrm{~J} / \mathrm{m}^{2}$ to $0.61 \mathrm{~J} / \mathrm{m}^{2}$ upon lithiation to $\mathrm{Li}_{7} \mathrm{Ti}_{5} \mathrm{O}_{12},{ }^{122}$ so it is conceivable that the lithiated orthorhombic $\mathrm{Li} \sim 0.5 \mathrm{TiO}_{2}$ phase has an average surface energy that is about $0.11 \mathrm{~J} / \mathrm{m}^{2}$ greater than the tetragonal anatase $\mathrm{TiO}_{2}$ phase.
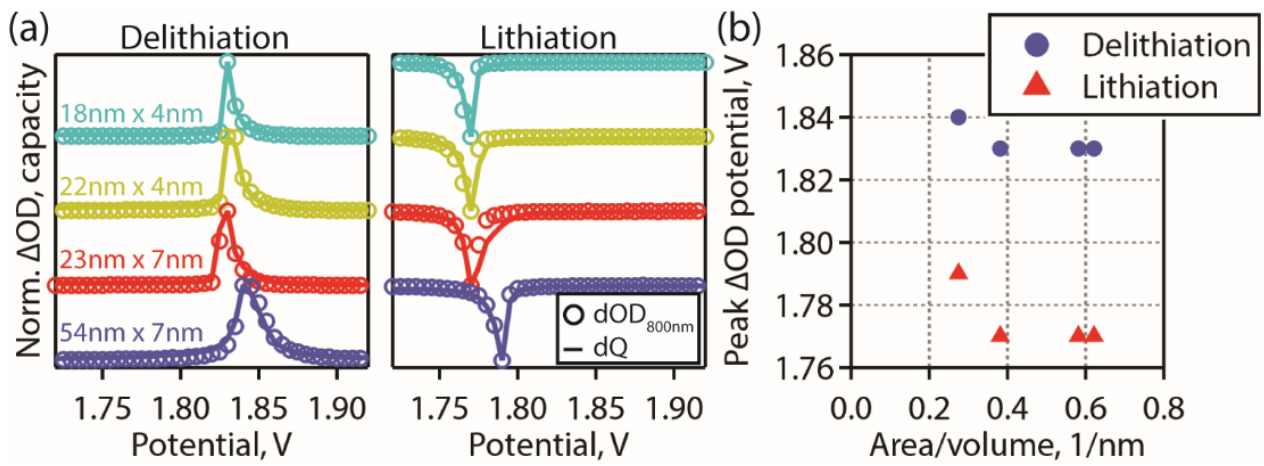

Figure 3. a) Integrated differential capacity across each $5 \mathrm{mV}$ potentiostatic charging step during PITT measurements of different $\mathrm{TiO}_{2}$ nanocrystal films, along with integrated changes in optical density at $800 \mathrm{~nm}$ for the lithiation and delithiation reactions. b) The voltages at the maximum integrated change in optical density are plotted against estimated area/volume ratios for the nanocrystal samples shown in (a).

Phase-field simulations of Li and phase boundary flux in single particles provide a more physical probe of the relationship between particle morphology and charging energetics. Phasefield simulations have been applied to $\mathrm{LiFePO}_{4}$ and $\mathrm{TiO}_{2}$ particles with excellent agreement to experiment. ${ }^{53,123,124}$ However, the effects of surface energy on Li-insertion reactions has received less attention, ${ }^{123}$ and the dependence of surface energy on $\mathrm{Li}$ concentration in $\mathrm{TiO}_{2}$ is poorly understood. Square prism particles of various sizes were tested with similar morphology to the nanoplatelets shown in Figure 1 (i.e. the $\{001\}$ facet was the dominant exposed plane). Particle width ranged from 15 to $50 \mathrm{~nm}$ across the $\{001\}$ facet, and the thickness was assumed to be thin enough to neglect gradients along the $<001\rangle$ direction. Earlier studies suggest that the boundary propagates along a strain-invariant facet, $\{010\}$, and that Li diffusion is isotropic in anatase but occurs mostly along $\langle 100\rangle$ in orthorhombic $\mathrm{Li}_{\sim 0.5} \mathrm{TiO}_{2}{ }^{125} \mathrm{Li}$ diffusion was assumed to be isotropic in these simulations, but a misfit strain at the coherent boundary between tetragonal and orthorhombic phases was modeled with an elastic energy tensor to capture the crystalline structure of the particles. Energies of the particle surfaces, bulk chemical potentials and Li concentration gradient energies were estimated and included in the simulation model as well (see Supporting Information).

Simulations demonstrate that size-dependent surface energies shift the critical potentials of (de)lithiation reactions in $\mathrm{TiO}_{2}$ nanocrystals. Figure 4a shows the critical overpotentials required for the two-phase transformation to occur upon both lithiation and delithiation. The effect of surface energy is tested by varying the surface energy difference, $\Delta \gamma$, between the anatase and 
orthorhombic phases. Simulation results confirm that smaller particles need lower (i.e. more negative) overpotentials for lithiation and delithiation when the surface energy of the lithiated phase is greater in magnitude than the anatase phase. A larger difference between the anatase and orthorhombic surface energies, $\Delta \gamma$, can enhance this size effect. With $\Delta \gamma=0.3 \mathrm{~J} / \mathrm{m}^{2}$, the reduction in critical overpotential upon reducing particle size from $50 \mathrm{~nm}$ to $25 \mathrm{~nm}$ is $5.5 \mathrm{mV}$ for lithiation and $2.7 \mathrm{mV}$ for delithiation (Figure 4a). In comparison, the critical overpotential differences observed experimentally between particles with lengths $53 \mathrm{~nm}$ and $23 \mathrm{~nm}$ are larger; roughly 20 $\mathrm{mV}$ for lithiation and $10 \mathrm{mV}$ for delithiation (Figure $\mathbf{4 b}$ ). The experimental size effect would be larger if the surface energy difference, $\Delta \gamma$, is greater than $0.3 \mathrm{~J} / \mathrm{m}^{2}$, or if macroscopic effects such as electrolyte polarization magnify the measured values. Nevertheless, simulations confirm that particle morphology can systematically tune (de)lithiation potentials in nanostructured $\mathrm{TiO}_{2}$ electrodes.

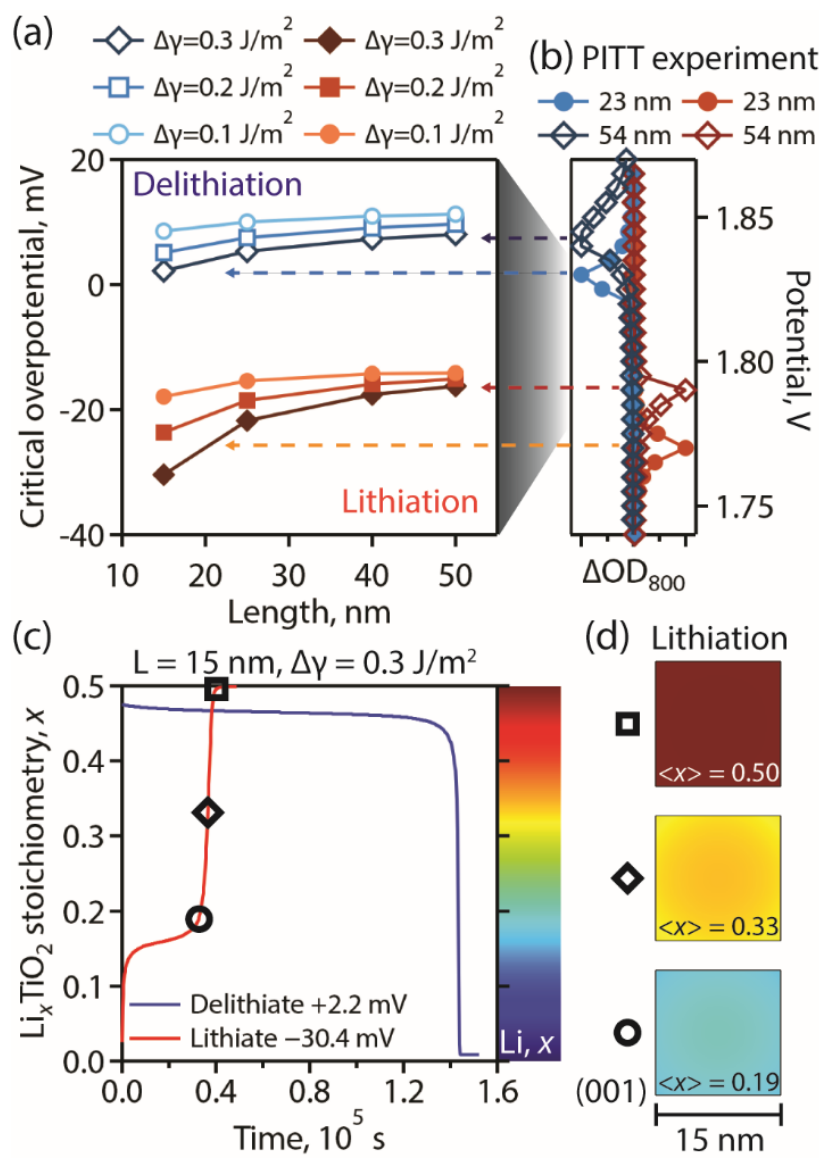

Figure 4. Phase field simulations of (de)lithiation in square $\mathrm{TiO}_{2}$ nanoplatelets of various sizes. a) Size dependence of the critical overpotential required for the two-phase transformation from anatase $\mathrm{Li}_{<0.2} \mathrm{TiO}_{2}$ to orthorhombic $\mathrm{Li}_{>0.5} \mathrm{TiO}_{2}$, with a range of surface energy differences, $\Delta \gamma$, between the two phases. b) Differential coloration measured during PITT of the nanocrystal samples of two different sizes $(23 \times 4 \mathrm{~nm}$ and $54 \times 7 \mathrm{~nm})$, identical to results from Figure 3a, shown as a qualitative comparison of the experimental and simulated effect of particle size on transformation potentials. c) Time evolution of the 
average Li concentration in $15 \mathrm{~nm}$ nanoplatelets during phase-field simulated charging at the critical overpotentials for lithiation and delithiation with a surface energy difference of $\Delta y=0.3 \mathrm{~J} / \mathrm{m}^{2}$. The markers on the lithiation curve correspond to the images in (d) showing the distribution of $\mathrm{Li}$ in simulated platelets during charging, quantified by the color bar in (c).

Polydispersity in particle size can explain the broadening observed in (de)lithiation peaks in coloration and differential charge during PITT. The peak potentials of the two-phase transformations during PITT are broadened by $20-30 \mathrm{mV}$ for each sample, with larger particles showing broader peaks (Figure 3). This distribution in measured potentials can be compared to the distribution in particle sizes shown in Figure 1. For instance, the smallest nanocrystals have an average size of $18 \times 4 \mathrm{~nm}$ and span a range of sizes from roughly $8 \times 2 \mathrm{~nm}$ to $34 \times 7 \mathrm{~nm}$ (Table S1). Phase field models suggest that the difference in critical (de)lithiation potentials between the smallest and largest particles should be at least $10 \mathrm{mV}$ (Figure 4a), or even greater if the size effect is augmented during experiments (Figure $\mathbf{4 b}$ ). Thus, particle size polydispersity may explain why the breadth of two-phase (de)lithiation peaks observed by PITT (FWHM $\approx 25 \mathrm{mV}$ ) is similar to the difference in peak critical potentials between the smallest and largest nanoplatelet films $\approx 20$ $\mathrm{mV})$. Polydispersity in the Li-insertion potentials between different particles in an ensemble electrode can have significant implications for charging kinetics ${ }^{126}$ and hysteresis. ${ }^{104-106}$

\section{Kinetic implications of nanocrystal ensemble polydispersity}

The practical performance of battery electrodes for fast-charging applications is limited not by equilibrium capacities, but by the kinetics of (dis)charging. The kinetic bottlenecks to charging during two-phase Li-insertion reactions are actively debated; it is unclear if nucleation barriers or bulk diffusion of Li or phase boundary propagation limit kinetics. ${ }^{54,127}$ Ensemble effects are also important to consider because local heterogeneity in potential or charge flux can have dramatic impacts on bulk properties of microcrystalline electrodes. ${ }^{64,126,128,129}$ Thus, the distribution of critical potentials and charging rates among an ensemble of particles can have significant practical consequences, even if the range of these differences among particles is minute. To examine the role of particle morphology and ensemble heterogeneity on charging kinetics we compared nonequilibrium in operando spectroelectrochemical measurements to continuum charging models and single-particle simulations.

The kinetics of (de)lithiation in nanocrystalline $\mathrm{TiO}_{2}$ films were probed by coloration during potentiostatic charging. To isolate the two-phase (de)lithiation reaction, which is responsible for half of the total charge capacity (Figure S4), the electrode was first equilibrated to a potential within the two-phase coexistence plateau. This technique provides two distinct advantages to probe reaction kinetics: the open circuit voltage (OCV) and state of coloration (SOCo) across the anataseorthorhombic reaction can be directly measured, and a precise overpotential can be applied to oxidize or reduce the ensemble. The SOCo was calculated by comparing the film's optical density to the extremes of coloration in fully oxidized $\left(+3.5 \mathrm{~V}\right.$ vs $\left.\mathrm{Li}^{2} / \mathrm{Li}^{+}\right)$and fully reduced $(+1.5 \mathrm{~V}$ vs $\left.\mathrm{Li} / \mathrm{Li}^{+}\right)$states, as illustrated in Figure 2b,c. The measured SOCo is analogous to the 
electrochemical state of charge (SOC), but only monitors charge compensation that induces coloration at $800 \mathrm{~nm}$ (i.e. only lithium insertion, no double layer capacitance).

The close correlation between optical and electrochemical signals during PITT (Figure 2) suggests that the SOCo at $800 \mathrm{~nm}$ is linearly related to the state of charging across the two-phase lithiation reaction. However, it is unclear if color correlates with the Li concentration or the anatase-orthorhombic crystalline phase fraction in individual particles. Similarly, optical transmission samples a large ensemble of nanocrystals and it is unclear what fraction of these particles are actively transforming during transient measurements. At steady-state, phase coexistence is not observed in $\mathrm{TiO}_{2}$ particles smaller than $100 \mathrm{~nm},{ }^{8,48}$ and phase-field simulations suggest that the transformation between anatase and orthorhombic phases occurs very quickly (Figure 4c). Thus, we assume that the ensemble of particles can be approximated as a discrete set of anatase and orthorhombic particles during charging, with a linear relationship between the ensemble phase fraction and the optical density of the film.

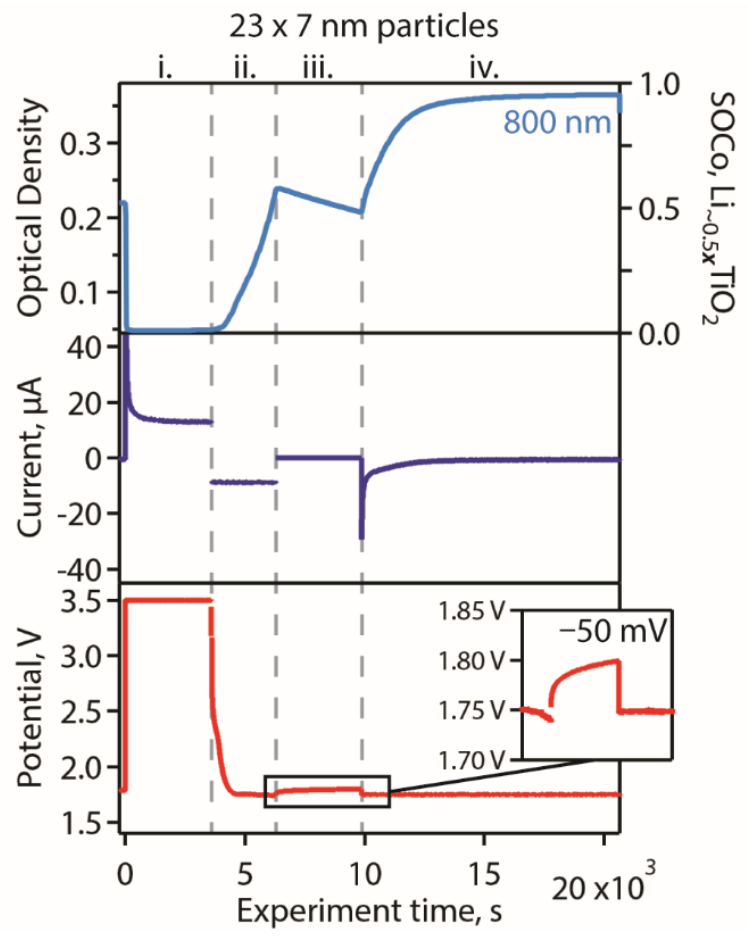

Figure 5. Optical density at $800 \mathrm{~nm}$, current and potential responses of a film of $7 \times 23 \mathrm{~nm}$ $\mathrm{TiO}_{2}$ nanocrystals during a spectroelectrochemical kinetics measurement. The film was first (i) oxidized to the delithiated $\mathrm{TiO}_{2}$ state, then (ii) reduced until partially transformed across the anatase-orthorhombic reaction, (iii) allowed to relax at open-circuit conditions, and (iv) charged at a fixed $-50 \mathrm{mV}$ overpotential.

Coloration at different wavelengths reveals the convoluted kinetics of different charging mechanisms in $\mathrm{TiO}_{2}$ nanocrystals. Figure 5 illustrates the spectroelectrochemical experiment for a film of $7 \times 23 \mathrm{~nm} \mathrm{TiO} 2$ nanoplatelets. The film was first equilibrated to roughly $50 \%$ SOCo across the anatase-orthorhombic transformation in open-circuit conditions, and charged at an 
overpotential of $+50 \mathrm{mV}$ relative to the relaxed potential. Figure 6a shows optical spectra at different points in the charging experiment, revealing the same distinct visible and near-IR transformations observed during equilibrium PITT experiments (Figure 2b). The optical signals at $800 \mathrm{~nm}$ and $2000 \mathrm{~nm}$ can be used to deconvolute the transient current response of the film, which may include electrode polarization, non-Faradaic and single-phase charging, and leakage currents (Figure 6b). ${ }^{130}$ A large spike in current at the beginning of charging correlates with a small transient increase in optical density at $2000 \mathrm{~nm}$ (Figure 6a,c). This optical signal indicates Drude-like extinction from accumulated electrons in $\mathrm{TiO}_{2}$ nanocrystals before the onset of lithium insertion. ${ }^{82}$ Coloration at $800 \mathrm{~nm}$, which directly probes the transformation from anatase $\mathrm{Li}<0.2 \mathrm{TiO}_{2}$ to orthorhombic $\mathrm{Li}_{\sim 0.5} \mathrm{TiO}_{2}$, follows different dynamics than the roughly exponential current response (Figure 6c). We can therefore use coloration to isolate the two-phase insertion reaction from other convoluting charging processes at an appropriate time resolution to observe in operando kinetics. This method to distinguish particular phase transformations in Li-insertion electrodes is comparable to in situ techniques such as X-ray diffraction (XRD) and X-ray spectroscopy (e.g. XANES), but can be implemented at more convenient scales with simple instrumentation and a variety of light-source and detector schemes to adjust spectral, spatial and temporal resolution.
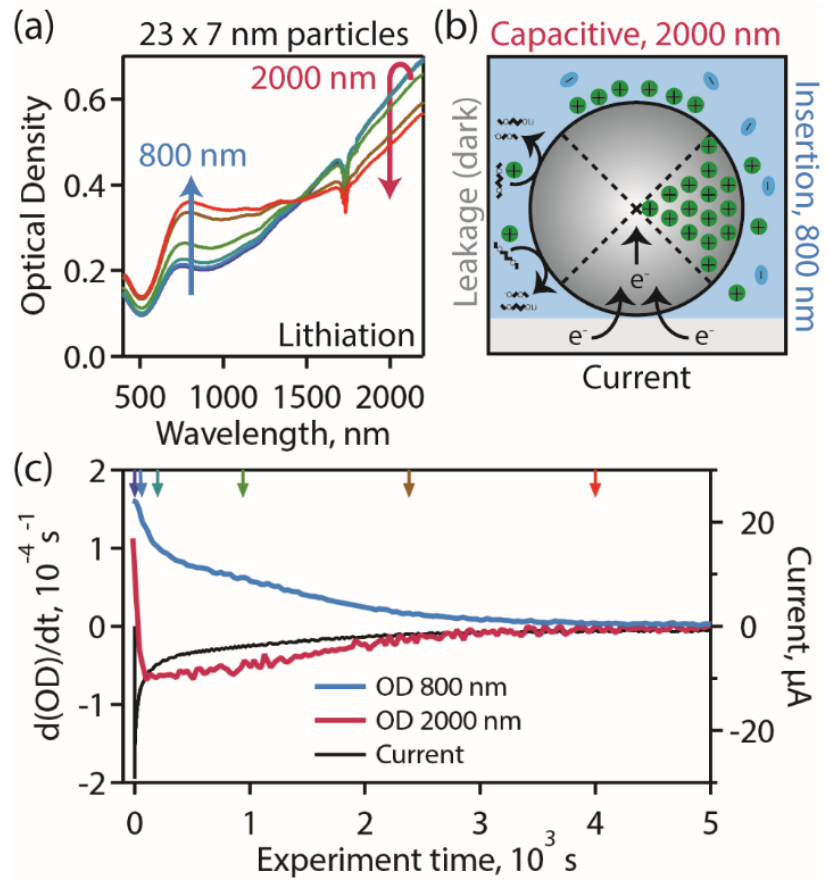

Figure 6. Optical response of a film of $7 \times 23 \mathrm{~nm} \mathrm{TiO} 2$ nanoplatelets during potentiostatic charging from a $50 \%$ initial state of $800 \mathrm{~nm}$ coloration. a) The change in optical coloration (800 $\mathrm{nm}$ and $2000 \mathrm{~nm}$ ) and current during the potentiostatic charging experiment. b) A schematic illustrating different charging mechanisms of $\mathrm{TiO}_{2}$ nanocrystals and their optical signatures. c) Optical transmittance of the film at different times after the start of the potentiostatic charging experiment (step iv. of Figure 5). The colored arrows in (c) indicate when the same color spectra shown in (a) were acquired. 
The kinetics of (de)lithiation depend strongly on the applied overpotential. Figure 7a shows the optical responses of a film of $7 \times 23 \mathrm{~nm} \mathrm{TiO}_{2}$ nanoplatelets conditioned to a $50 \%$ SOCo across the anatase-orthorhombic transition and charged at different oxidizing and reducing overpotentials. A measurement of the electrochemical charge, rather than coloration, during this experiment would be convoluted by leakage and surface charging processes, and require mathematical deconvolution to isolate the Li-insertion reaction. ${ }^{130}$ The optical response is roughly exponential for all trials (Figure S13), but larger overpotentials increase the rate of transformation. It is unclear if the nucleation rate of the two-phase reaction, or flux of either Li or the two-phase boundary during transformations, are responsible for this dependence on potential.

The rate-limitations of nucleation or growth kinetics are quantified by fitting the data to a Johnson-Mehl-Avrami-Kolmogorov (JMAK) continuum phase-transition model. The JMAK model, described in detail in the Supporting Information, has been effectively used to model transformation kinetics of nanocrystalline electrodes that undergo two-phase Li-insertion, such as $\mathrm{LiFePO}_{4}{ }^{54,124,131}$ The model accounts for both nucleation and growth rates, and is described by an adjusted exponential:

$$
\operatorname{SOCo}(t)=1-\exp \left[-(k t)^{n}\right]
$$

The prefactor $k$ is the general reaction rate, and $n$ is commonly interpreted as a measure of how growth or nucleation limits reaction kinetics. The value of $n$ ranges from 1 , for a nucleation-limited reaction or growth-limited reaction with $1 \mathrm{D}$ phase propagation, to a value of 4 for a system that transforms through 3D growth at a constant nucleation rate. ${ }^{54,132}$ An additional parameter, $S O C o$ final $\left(\right.$ i.e. $\left.S O C o(t \rightarrow \infty), 0<S O C o_{\text {final }}<1\right)$, was also included (see Supporting Information) to account for incomplete transformations of the ensemble observed at small overpotentials (Figure 7a). As described previously, the critical potential for transformation varies $20-30 \mathrm{mV}$ across the distribution of particle sizes present in each film (Figure 3a), so only a subset of nanocrystals will transform for small overpotentials $(<40 \mathrm{mV}$, Figure $7 \mathbf{b})$. Although the JMAK model assumes a perfectly homogeneous medium, rather than the discrete ensemble of particles tested, the model successfully fits the charging data for a range of applied overpotentials with only three free variables.

Charging kinetics are remarkably consistent between films of different particle morphologies. Figure $\mathbf{7 b}$ compares fitted parameters for different nanocrystal samples across a range of applied overpotentials. SOCofinal, $n$ and $k$ all have a similar dependence on applied overpotential for all nanocrystal samples without any systematic dependence on size or shape. The exponent $n$, which measures the balance between nucleation and growth limitations during the transformation, ranges between 1 and 1.3 at larger overpotentials. JMAK theory indicates that either the transformation is nucleation-limited, with rapid growth along phase-boundaries, or 1D growth is rate-limiting. ${ }^{54,132}$ At low reducing overpotentials sub-exponential behavior is observed $(n<1)$ which departs from the analytical limits of JMAK theory. In this regime, non-unity values of SOCofinal reflect the ensemble polydispersity of the film, and depart from the assumptions of homogeneity used to derive the JMAK model, so the fitted values should be treated as an empirical comparison. Fitted $n$ and $k$ values show minor asymmetry in lithiation and delithiation directions for some samples, but this effect is inconsistent for each nanocrystal film. Despite different $\mathrm{Li}$ 
diffusivity, miscibility and crystallinity of the anatase and $\mathrm{Li}_{\sim 0.5} \mathrm{TiO}_{2}$ phases ${ }^{53,60,125}$ we observe fairly similar behavior upon both lithiation and delithiation in these films.

Measurements of films prepared by different processing routes indicate that bulk film polarization and surface chemistry have little effect on charging kinetics. Electrode films ranging in thickness from $80 \mathrm{~nm}$ to $210 \mathrm{~nm}$ (Table S2) yielded very similar charging kinetics (Figure 6, Figure S14), suggesting that bulk film polarization has a negligible impact. Different nanocrystal surface chemistry treatments also had little effect. For three of the electrodes $(4 \times 18,4 \times 22$, and $7 \times 23 \mathrm{~nm}$ nanoplatelets, Figure 1b), films were immersed in a formic acid (FA) solution to replace native oleic acid ligands with smaller FA ligands. ${ }^{74,133}$ In the other electrode $(7 \times 54 \mathrm{~nm})$, dispersed $\mathrm{TiO}_{2}$ nanocrystals were exposed to nitrosyltetrafluoroborate $\left(\mathrm{NOBF}_{4}\right)$ in solution to exchange oleic acid ligands with more conductive species before film deposition. ${ }^{75}$ The fitted kinetics were indistinguishable between all four samples (Figure 6b). Moreover, annealing a FA-treated film of $4 \times 22 \mathrm{~nm}$ nanoplatelets at $300^{\circ} \mathrm{C}$ in argon for $1 \mathrm{hr}$ had negligible impacts on charging kinetics (Figure S15). Charging rates (i.e., the fitted $k$ parameter) were found to decrease during lithiation in a $10 \times$ diluted electrolyte without significant changes in the fitted exponential shape parameter, $n$ (Figure S16).
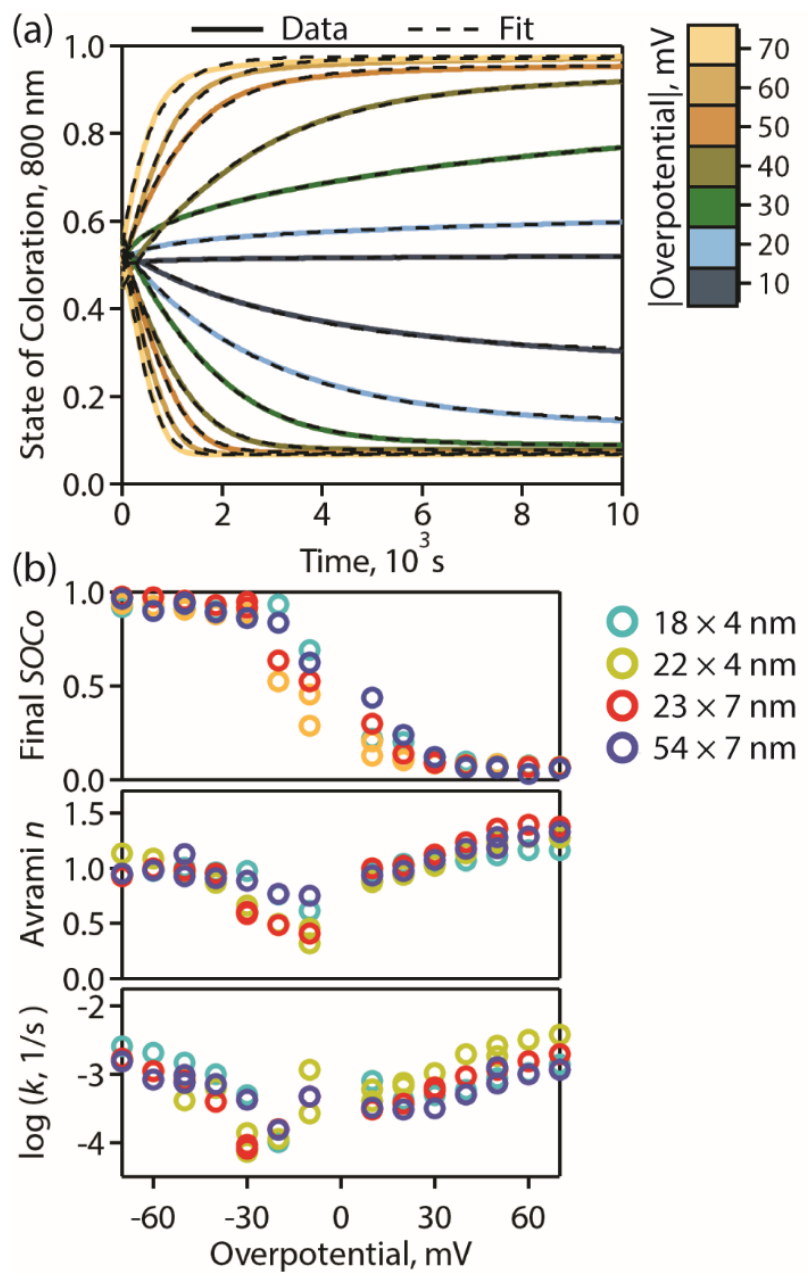
Figure 7. a) The state of coloration ( $S O C o$ ) for a $23 \times 7 \mathrm{~nm}$ nanoplatelet film, derived from optical density at $800 \mathrm{~nm}$, is plotted as a function of time during potentiostatic charging. The $S O C o$ is defined such that $S O C o=1$ is the fully darkened (i.e., lithiated, $\mathrm{Li}_{\sim 0.5} \mathrm{TiO}_{2}$ ) film, and $S O C o=0$ is the fully transparent (delithiated, $\mathrm{TiO}_{2}$ ) film. Measured kinetics were fitted to a modified JMAK model, yielding b) fit parameters of the final SOCo, Avrami exponent $n$ and rate prefactor, $k$, for different overpotentials and nanocrystal sizes.

It is unlikely that $\mathrm{Li}$ diffusion within $\mathrm{TiO}_{2}$ nanocrystals is rate-limiting during charging. The JMAK model fits the data with $n \approx 1$ (Figure 6b), which can be due to either nucleation-limited or 1D growth-limited kinetics. Growth may be limited by any continuum transport process, including Li diffusion in particles, propagation of the two-phase boundary, Li diffusion across a solid-electrolyte interface (SEI), or even mesoscopic diffusion between particles. Estimates of Li diffusion parameters in anatase $\mathrm{TiO}_{2}$ and orthorhombic $\mathrm{Li} \sim 0.5 \mathrm{TiO}_{2}$ vary tremendously; $\mathrm{Li}$ diffusivities in both anatase and orthorhombic phases have been estimated to range from $10^{-17}-$ $10^{-10} \mathrm{~cm}^{2} / \mathrm{s}$, depending on the sample preparation and characterization method. ${ }^{10,53,60,62,125,134-137}$ This wide range may be due to the limitations of different measurement techniques. Single crystals of anatase $\mathrm{TiO}_{2}$ have shown diffusivities of $2 \times 10^{-13}$ and $6 \times 10^{-13} \mathrm{~cm}^{2} / \mathrm{s}$ for lithiation and delithiation, respectively, through chronoamperometry. ${ }^{134,135}$ However, similar measurements of nanoporous anatase $\mathrm{TiO}_{2}$ find much smaller diffusivities of $1 \times 10^{-17}$ and $4 \times 10^{-17} \mathrm{~cm}^{2} / \mathrm{s}$ for lithiation and delithiation, respectively. ${ }^{62}$ These measurements probe transport across the entire electrode, but microscopic measurements of diffusion through solid state NMR of nanocrystalline $\mathrm{TiO}_{2}$ suggest much higher diffusivities: $4.7 \times 10^{-12} \mathrm{~cm}^{2} / \mathrm{s}$ for anatase $\mathrm{TiO}_{2}$ and $1.3 \times 10^{-11} \mathrm{~cm}^{2} / \mathrm{s}$ for orthorhombic $\mathrm{Li}_{0.5} \mathrm{TiO}_{2}{ }^{60}$ Thus, the literature indicates that mesoscopic Li diffusion across or around particle interfaces is much slower than diffusion within $\mathrm{TiO}_{2}$ nanocrystals. This conclusion is supported by measurements of our $\mathrm{TiO}_{2}$ nanocrystal films (Figure 7). JMAK fits of charging data reduce to a simple exponential model of $1 \mathrm{D}$ diffusion if $n=1$, where diffusivity can be estimated from the exponential prefactor: $k \approx \pi \mathcal{D}_{L i} / L^{2}$. Here, $L$ is the characteristic length of diffusion. Estimated diffusivities range from about $5 \times 10^{-17} \mathrm{~cm}^{2} / \mathrm{s}$ for $L=5 \mathrm{~nm}$ to about $5 \times 10^{-15}$ $\mathrm{cm}^{2} / \mathrm{s}$ for $L=50 \mathrm{~nm}$. These values are comparable to diffusivities measured previously in nanoporous films, but much lower than diffusivities measured within $\mathrm{TiO}_{2}$ particles. Given that inter-particle transport is apparently rate limiting, at these particle sizes, measured charging rates would vary tremendously between ensembles of different sized nanocrystals if slow Li diffusion within particles were rate-limiting.

Phase-field simulations indicate that slow single-phase (de)lithiation prior to the two-phase transformation limits kinetics in single particles. Figure $\mathbf{4} \mathbf{c}$ tracks the time evolution of the average $\mathrm{Li}$ concentration (i.e. SOCo) in single particles of different sizes. The sharp increase in rate from low to high Li content - across the anatase to orthorhombic phase transition - demonstrates that phase-boundary propagation and Li diffusion are fast once a critical Li concentration is achieved. Similar behavior is observed for particles as large as $50 \mathrm{~nm}$, and at larger overpotentials (Figure S12). This result can be explained by the relatively large gradient coefficient, $\kappa$, which penalizes phase coexistence in a single particle (Supporting Information). This parameter was estimated based on earlier observations that small $\mathrm{TiO}_{2}$ nanocrystals $(<100 \mathrm{~nm})$ do not exhibit coherent coexistence of anatase and orthorhombic phases at steady state. ${ }^{8,53}$ As a result, the Li concentration is quite homogeneous across the particle during charging, even within the miscibility gap between 
the anatase and orthorhombic phases (Figure 4d). The rate limiting step during (de)lithiation is therefore slow Li-insertion before the crystalline phase transformation. The kinetics of singlephase Li-insertion depend on Li activity at the particle surface, which accounts for the observed effects of overpotential (Figure 7b) and electrolyte concentration (Figure S16) on rate. Thus, even if a two-phase transformation is thermodynamically favorable at a critical overpotential, the particle requires time to slowly exchange $\mathrm{Li}$ with the electrolyte (or nearby particles) until it reaches a critical Li content for rapid two-phase transformation. Single-phase Li accumulation may be considered as a form of nucleation prior to the two-phase anatase-orthorhombic reaction, but it need not obey the kinetics of classical nucleation theory. We note that prior phase field simulations of $\mathrm{Li}$ insertion in $\mathrm{TiO}_{2}$ nanocrystals simulated galvanostatic charging, ${ }^{53}$ so the discontinuous kinetics shown in Figure 4c would not have been observed.

The time required to achieve critical $\mathrm{Li}$ content in $\mathrm{TiO}_{2}$ particles for the two-phase transformation would manifest as a nucleation barrier in fits of the experimental data. Optical measurements of charging kinetics are sensitive to the rapid two-phase transformation from anatase $\mathrm{Li}<0.2 \mathrm{TiO}_{2}$ to orthorhombic $\mathrm{Li} \sim 0.5 \mathrm{TiO}_{2}$; single phase reactions beyond this transformation are not as well-resolved because the change in Li content is much smaller. Increasing the critical overpotential creates a larger gradient to hasten the single-phase (de)lithiation of each particle, as shown in Figure S12. The observed JMAK fits of $n \approx 1$ can therefore be attributed to 'nucleation'limited kinetics defined by the single-phase conditioning time prior to rapid two-phase transformation. This result also indicates that the ensemble electrode is a population of fully anatase or orthorhombic particles, undergoing stochastic changes in number density during charging. In this case, only a small concentration of particles actively transforming between the two-phases. We expect that at some larger overpotential $(>100 \mathrm{mV})$ this 'nucleation' rate will become comparable to the two-phase transformation rate and alter the observed behavior.

The initial distribution of $\mathrm{Li}$ and phases among particles in the ensemble electrode (i.e. the initial $S O C o$ ) has a significant impact on (de)lithiation kinetics. Figure 8a shows potentiostatic responses, measured by optical coloration, of a $7 \times 53 \mathrm{~nm}$ nanoplatelet film to applied $\pm 50 \mathrm{mV}$ overpotentials from several initial SOCo values. The initial SOCo measures the fraction of nanocrystals in the anatase or orthorhombic phases among the ensemble, rather than the true $\mathrm{Li}$ concentration, and is recorded after $3 \mathrm{hr}$ of open-circuit relaxation. Fitted rates, $k$, are shown in Figure 8b, and other fit parameters are shown in Figure S14. The initial absolute potential varies by only about $10 \mathrm{mV}$ across a wide range of initial SOCo conditions (Figure $\mathbf{S 1 4 b}$ ), which is similar to the range of critical transformation potentials measured between the different nanocrystal ensembles (Figure 3). Fitted $k$ and $n$ parameters were found to be independent of one another (Figure S14c). A logarithmic relationship between $k$ (i.e. charging rate) and initial SOCo is observed for all films (Figure 8b), with different behavior during lithiation ( $\log k=$ $\left.0.51\left(S O C o_{\text {initial }}\right)-3.31, \mathrm{R}^{2}=0.39\right)$ and delithiation $\left(\log k=-1.06\left(S O C o_{\text {initial }}\right)-2.26, \mathrm{R}^{2}=\right.$ 0.65). During lithiation, the transformation rate moderately increases with greater initial SOCo (i.e. more initial Li). Conversely, during delithiation the transformation rate increases dramatically, by nearly an order of magnitude, with a lower initial SOCo (i.e. less initial Li). The fitted $n$ parameter also differs in the lithiation and delithiation directions; $n$ is fairly consistent across different initial SOCo upon delithiation, but decreases as $S O C o$ approaches 1 (i.e. mostly $\mathrm{Li}_{\sim 0.5} \mathrm{TiO}_{2}$ ) upon lithiation. 

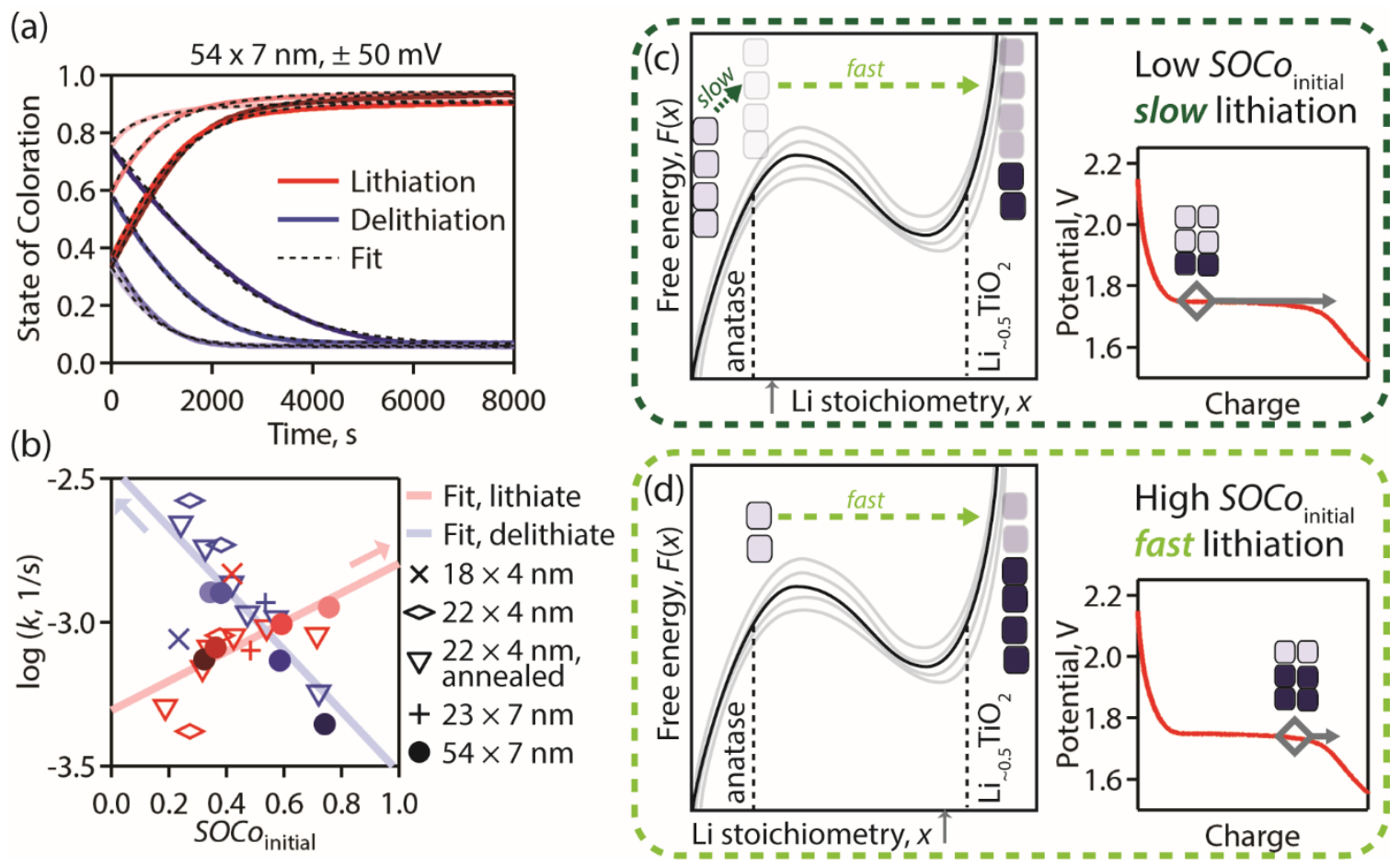

Figure 8. The effects of initial state of $800 \mathrm{~nm}$ coloration $\left(S O C o_{\text {initial }}\right)$ on Li-insertion kinetics. a) The potentiostatic response of $S O C o$ for a $53 \times 7 \mathrm{~nm}$ nanoplatelet film, derived from optical density at $800 \mathrm{~nm}$, is plotted as a function of time during potentiostatic charging from different $S O C o_{\text {initial }}$ with $\pm 50 \mathrm{mV}$ overpotentials. b) A comparison of the fitted rate constant, $k$, with $S O C o_{\text {initial }}$ for different samples. Linear regressions are shown for the results of lithiation (red) and delithiation (blue) experiments. The filled-in circles correspond to the measurements plotted in the same colors shown in (a). Schematics of the free energies of $\mathrm{TiO}_{2}$ particles across the anatase $\mathrm{Li}_{<0.2} \mathrm{TiO}_{2}$ (light blue-gray) to orthorhombic $\mathrm{Li}_{\sim 0.5} \mathrm{TiO}_{2}$ (dark blue) phase transformation, illustrating the effect of $S O C o_{\text {initial }}$ on macroscopic lithiation rates for nanocrystalline ensembles with either c) low $S O C o_{\text {initial }}$ or d) high $S O C o_{\text {initial. }}$ Light gray traces in the free energy diagrams illustrate the distribution of single-particle profiles, and the black trace is the average free energy profile.

The relationship between initial SOCo and charging rates can be attributed to slow single-phase 'nucleation' of particles within a heterogeneous ensemble. The initial SOCo illustrated in Figure $\mathbf{8 b}$ is reached by galvanostatic charging and relaxation at open circuit for an hour (Figure 5), allowing Li chemical potential gradients to equilibrate within and between particles. Thus, particles that exceed the critical overpotential for transformation (Figure 4a) have enough time to reach the critical Li content and undergo the two-phase transformation. Concurrently, local potentials in the film will adjust to accommodate local variations in Li chemical potential until each particle equilibrates to a stable Li composition across the miscibility gap. The distribution of critical transformation potentials (Figure 3) among nanocrystals of different sizes in ensemble electrodes will further contribute to this local charging heterogeneity. The Li content in each 
particle that hasn't yet transformed should increase with the initial SOCo. Particles closer to the critical Li composition can be described as 'nucleated' by JMAK or other statistical theories. For instance, during lithiation the film with a higher initial SOCo will charge more quickly because the remaining particles require less single-phase 'nucleation' before transforming to orthorhombic $\mathrm{Li}_{\sim 0.5} \mathrm{TiO}_{2}$. These trends with initial SOCo are retained even in a more dilute electrolyte, albeit at slower overall rates (Figure S16).

The slow single-phase kinetics observed in $\mathrm{TiO}_{2}$ nanocrystals have important practical implications for ensemble electrodes. A kinetic 'nucleation' barrier can distort measured potentials during cycling, which is problematic for battery control systems that rely on potential to determine the state of charge. In Li-ion battery electrode materials with a large Li miscibility gap, such as anatase $\mathrm{TiO}_{2},{ }^{105,106} \mathrm{Li}_{4} \mathrm{Ti}_{5} \mathrm{O}_{12},{ }^{104,138}$ and $\mathrm{LiFePO}_{4},{ }^{104}$ activation barriers for the phase transformation manifest as a hump in the galvanostatic potential plateau (e.g. the $\mathrm{C} / 1$ rate delithiation response in Figure S4), or as polarization during GITT (Figure S5a,b). The magnitude and state of charge of this hump is influenced by recent charging history (the 'memory effect'), and is described as a stochastic phenomenon that arises from non-equilibrium chemical potential heterogeneity between particles. ${ }^{104-106,138}$ Similarly, a kinetic 'nucleation' barrier may explain why the fraction of actively-transforming particles in an ensemble electrode is determined by the charging rate. Charging heterogeneity can accelerate capacity fade due to local current hotspots, ${ }^{126}$ so the active particle population has important practical consequences for batteries. For instance, ensembles of LFP microparticles transform particle-by-particle at low charging rates, but concurrently across the entire ensemble at high rates. ${ }^{126}$ This phenomenon is attributed to a distribution of activation 'barriers' to phase transformation in the ensemble. Discontinuous kinetic bottlenecks, as observed in polydisperse ensembles of $\mathrm{TiO}_{2}$ nanocrystals, are a plausible explanation for this behavior. A careful accounting of the charging kinetics for different processes in ensemble Li-ion electrodes will thus be essential to improve the performance of next-generation batteries.

\section{Conclusions}

A combination of in situ spectroelectrochemical experiments probe the equilibrium and transient responses of Li-insertion in size-controlled $\mathrm{TiO}_{2}$ nanoplatelet films. Colloidal synthesis and thin-film processing yield transparent nanocrystalline anatase $\mathrm{TiO}_{2}$ electrodes with precisely defined particle morphology, polydispersity, and film characteristics. Distinct electrochromic coloration is observed in the visible and infrared for Li-insertion transformations (anatase $\mathrm{Li}_{<0.2} \mathrm{TiO}_{2}$ to orthorhombic $\mathrm{Li}_{\sim 0.5} \mathrm{TiO}_{2}$ ) and capacitive electron accumulation, respectively. Thus, a direct in operando measurement of the Li-insertion reaction is enabled, without convoluting effects from electrolyte leakage or double-layer capacitance. The equilibrium potential of the Liinsertion transformation is observed to vary with nanocrystal size. Phase field simulations indicate that a difference in surface energies between the anatase and lithiated $\mathrm{TiO}_{2}$ phases causes this systematic dependence between particle size and transformation potential. Polydispersity in particle size can thus induce a distribution of local Li-insertion transformation potentials in nanocrystalline $\mathrm{TiO}_{2}$ ensembles. However, particle size has a negligible effect on Li-insertion 
kinetics during potentiostatic charging experiments. In operando measurements reveal that charging rates are sensitive to both applied overpotential and the initial state of charge of the nanocrystal film. The closer a film is to fully transformed, the faster the Li-insertion transformation will occur, for either the lithiation or delithiation reactions. A model of discontinuous charging kinetics is proposed based on phase field models: Li-insertion kinetics are limited by slow singlephase (de)lithiation to reach a critical Li concentration prior to rapid two-phase transformations between anatase $\mathrm{Li}_{<0.2} \mathrm{TiO}_{2}$ and orthorhombic $\mathrm{Li}_{\sim 0.5} \mathrm{TiO}_{2}$. During practical, intermittent cycling of nanocrystalline electrodes such as anatase $\mathrm{TiO}_{2}$, discontinuous charging kinetics can have important effects on charging heterogeneity and hysteresis. More generally, anatase $\mathrm{TiO}_{2}$ serves as a model Li-insertion electrode material and these results may be broadly applicable to other ensemble electrodes that undergo two-phase lithiation reactions.

\section{Supporting Information}

Experimental methods, statistics of $\mathrm{TiO}_{2}$ nanoplatelet size dispersity, powder X-ray diffraction patterns, film thicknesses, cyclic voltammetry (CV) measurements for each nanoplatelet film, chronopotentiometric $(\mathrm{CP})$ measurements, galvanostatic intermittent titration technique (GITT) measurements, potentiostatic intermittent titration technique (PITT) measurements of films not shown in the main text, more detail about estimations of particle surface energy, details of single-particle phase-field simulations and additional figures comparing the effects of different simulation parameters, more detail about the JMAK kinetic model, JMAK fit parameters of films not shown in the main text, a test of the effects of film annealing on Li-insertion charging kinetics, kinetic measurements of films charged in a diluted electrolyte.

\section{Acknowledgments}

This research was supported by the National Science Foundation (CHE-1905263), Lockheed Martin (UTA19-000624), Companhia Brasileira de Metallurgia e Mineração (CBMM, UTA16000941), and the Welch Foundation (F-1848). YZ and MT are supported by DOE Basic Energy Sciences Office under project number DE-SC0019111.

Notes: The authors declare the following competing financial interests: D.J.M. has a financial interest in Heliotrope Technologies, a company pursuing commercial development of electrochromic devices. 


\section{References}

(1) Scrosati, B.; Garche, J. Lithium Batteries: Status, Prospects and Future. J. Power Sources 2010, 195, 2419-2430.

(2) Howell, D.; Boyd, Steven; Duong, Tien Q.; Faguy, Peter W.; Cunningham, Brian; Gillard, Samuel. Batteries; Annual Progress Report 2018; US Department of Energy, Office of Energy Efficiency and Renewable Energy, Vehicle Technologies Office, 2019.

(3) Bresser, D.; Hosoi, K.; Howell, D.; Li, H.; Zeisel, H.; Amine, K.; Passerini, S. Perspectives of Automotive Battery R\&D in China, Germany, Japan, and the USA. $J$. Power Sources 2018, 382, 176-178.

(4) Thackeray, M. M.; Wolverton, C.; Isaacs, E. D. Electrical Energy Storage for Transportation-Approaching the Limits of, and Going beyond, Lithium-Ion Batteries. Energy Environ. Sci. 2012, 5, 7854-7863.

(5) Whittingham, M. S. Ultimate Limits to Intercalation Reactions for Lithium Batteries. Chem. Rev. 2014, 114, 11414-11443.

(6) Ohzuku, T.; Takehara, Z.; Yoshizawa, S. Nonaqueous Lithium/Titanium Dioxide Cell. Electrochim. Acta 1979, 24, 219-222.

(7) Huang, S. Y.; Kavan, L.; Exnar, I.; Grätzel, M. Rocking Chair Lithium Battery Based on Nanocrystalline $\mathrm{TiO}_{2}$ (Anatase). J. Electrochem. Soc. 1995, 142, L142-L144.

(8) Wagemaker, M.; Borghols, W. J. H.; Mulder, F. M. Large Impact of Particle Size on Insertion Reactions. A Case for Anatase $\mathrm{Li}_{\mathrm{x}} \mathrm{TiO}_{2}$. J. Am. Chem. Soc. 2007, 129, 43234327.

(9) Liu, H.; P. Grey, C. Influence of Particle Size, Cycling Rate and Temperature on the Lithiation Process of Anatase $\mathrm{TiO}_{2}$. J. Mater. Chem. A 2016, 4, 6433-6446.

(10) Ha, J. U.; Lee, J.; Abbas, M. A.; Lee, M. D.; Lee, J.; Bang, J. H. Designing Hierarchical Assembly of Carbon-Coated $\mathrm{TiO}_{2}$ Nanocrystals and Unraveling the Role of $\mathrm{TiO}_{2} / \mathrm{Carbon}$ Interface in Lithium-Ion Storage in $\mathrm{TiO}_{2}$. ACS Appl. Mater. Interfaces 2019, 11, 1139111402 .

(11) Lee, D.-H.; Lee, B.-H.; Sinha, A. K.; Park, J.-H.; Kim, M.-S.; Park, J.; Shin, H.; Lee, K.S.; Sung, Y.-E.; Hyeon, T. Engineering Titanium Dioxide Nanostructures for Enhanced Lithium-Ion Storage. J. Am. Chem. Soc. 2018, 140, 16676-16684.

(12) Sudant, G.; Baudrin, E.; Larcher, D.; Tarascon, J.-M. Electrochemical Lithium Reactivity with Nanotextured Anatase-Type $\mathrm{TiO}_{2}$. J. Mater. Chem. 2005, 15, 1263-1269. 
(13) Lui, G.; Li, G.; Wang, X.; Jiang, G.; Lin, E.; Fowler, M.; Yu, A.; Chen, Z. Flexible, Three-Dimensional Ordered Macroporous $\mathrm{TiO}_{2}$ Electrode with Enhanced ElectrodeElectrolyte Interaction in High-Power Li-Ion Batteries. Nano Energy 2016, 24, 72-77.

(14) Murphy, D. W.; Cava, R. J.; Zahurak, S. M.; Santoro, A. Ternary $\mathrm{Li}_{\mathrm{x}} \mathrm{TiO}_{2} \mathrm{Phases} \mathrm{from}$ Insertion Reactions. Solid State Ion. 1983, 9-10, 413-417.

(15) Kim, H.; Choi, W.; Yoon, J.; Um, J. H.; Lee, W.; Kim, J.; Cabana, J.; Yoon, W.-S. Exploring Anomalous Charge Storage in Anode Materials for Next-Generation Li Rechargeable Batteries. Chem. Rev. 2020.

(16) Fleischmann, S.; Mitchell, J. B.; Wang, R.; Zhan, C.; Jiang, D.; Presser, V.; Augustyn, V. Pseudocapacitance: From Fundamental Understanding to High Power Energy Storage Materials. Chem. Rev. 2020.

(17) Jung, S.-K.; Hwang, I.; Chang, D.; Park, K.-Y.; Kim, S. J.; Seong, W. M.; Eum, D.; Park, J.; Kim, B.; Kim, J.; et al. Nanoscale Phenomena in Lithium-Ion Batteries. Chem. Rev. 2020, 120, 6684-6737.

(18) Grey, C. P.; Tarascon, J. M. Sustainability and in Situ Monitoring in Battery Development. Nat. Mater. 2017, 16, 45-56.

(19) Boebinger, M. G.; Lewis, J. A.; Sandoval, S. E.; McDowell, M. T. Understanding Transformations in Battery Materials Using in Situ and Operando Experiments: Progress and Outlook. ACS Energy Lett. 2019, 335-345.

(20) Liu, D.; Shadike, Z.; Lin, R.; Qian, K.; Li, H.; Li, K.; Wang, S.; Yu, Q.; Liu, M.; Ganapathy, S.; et al. Review of Recent Development of In Situ/Operando Characterization Techniques for Lithium Battery Research. Adv. Mater. 2019, 0, 1806620.

(21) Barai, A.; Uddin, K.; Dubarry, M.; Somerville, L.; McGordon, A.; Jennings, P.; Bloom, I. A Comparison of Methodologies for the Non-Invasive Characterisation of Commercial Li-Ion Cells. Prog. Energy Combust. Sci. 2019, 72, 1-31.

(22) Bak, S.-M.; Shadike, Z.; Lin, R.; Yu, X.; Yang, X.-Q. In Situ/Operando SynchrotronBased X-Ray Techniques for Lithium-Ion Battery Research. NPG Asia Mater. 2018, 10, 563-580.

(23) Sandhya, C. P.; John, B.; Gouri, C. Lithium Titanate as Anode Material for Lithium-Ion Cells: A Review. Ionics 2014, 20, 601-620.

(24) Liu, Jiehua; Wei, Xiangfeng; Meng, Fancheng. Lithium Titanate Based Lithium-Ion Batteries. In Advanced Battery Materials; John Wiley \& Sons, Ltd, 2019; pp 87-158. 
(25) Zhao, B.; Ran, R.; Liu, M.; Shao, Z. A Comprehensive Review of $\mathrm{Li}_{4} \mathrm{Ti}_{5} \mathrm{O}_{12}$-Based Electrodes for Lithium-Ion Batteries: The Latest Advancements and Future Perspectives. Mater. Sci. Eng. R Rep. 2015, 98, 1-71.

(26) Kim, C.; Norberg, N. S.; Alexander, C. T.; Kostecki, R.; Cabana, J. Mechanism of Phase Propagation During Lithiation in Carbon-Free $\mathrm{Li}_{4} \mathrm{Ti}_{5} \mathrm{O}_{12}$ Battery Electrodes. Adv. Funct. Mater. 2013, 23, 1214-1222.

(27) Odziomek, M.; Chaput, F.; Rutkowska, A.; Świerczek, K.; Olszewska, D.; Sitarz, M.; Lerouge, F.; Parola, S. Hierarchically Structured Lithium Titanate for Ultrafast Charging in Long-Life High Capacity Batteries. Nat. Commun. 2017, 8, 1-7.

(28) Wang, C.; Wang, S.; Tang, L.; He, Y.-B.; Gan, L.; Li, J.; Du, H.; Li, B.; Lin, Z.; Kang, F. A Robust Strategy for Crafting Monodisperse $\mathrm{Li}_{4} \mathrm{Ti}_{5} \mathrm{O}_{12}$ Nanospheres as Superior Rate Anode for Lithium Ion Batteries. Nano Energy 2016, 21, 133-144.

(29) Kim, S. J.; Chang, D.; Zhang, K.; Graham, G.; Van der Ven, A.; Pan, X. Accordion Strain Accommodation Mechanism within the Epitaxially Constrained Electrode. ACS Energy Lett. 2018, 3, 1848-1853.

(30) Hua, X.; Liu, Z.; Fischer, M. G.; Borkiewicz, O.; Chupas, P. J.; Chapman, K. W.; Steiner, U.; Bruce, P. G.; Grey, C. P. Lithiation Thermodynamics and Kinetics of the TiO 2(B) Nanoparticles. J. Am. Chem. Soc. 2017, 139, 13330-13341.

(31) Ren, Y.; Liu, Z.; Pourpoint, F.; Armstrong, A. R.; Grey, C. P.; Bruce, P. G. Nanoparticulate $\mathrm{TiO}_{2}(\mathrm{~B})$ : An Anode for Lithium-Ion Batteries. Angew. Chem. Int. Ed. 2012, 51, 2164-2167.

(32) Liu, H.; Bi, Z.; Sun, X.-G.; Unocic, R. R.; Paranthaman, M. P.; Dai, S.; Brown, G. M. Mesoporous $\mathrm{TiO}_{2}-\mathrm{B}$ Microspheres with Superior Rate Performance for Lithium Ion Batteries. Adv. Mater. 2011, 23, 3450-3454.

(33) Beuvier, T.; Richard-Plouet, M.; Mancini-Le Granvalet, M.; Brousse, T.; Crosnier, O.; Brohan, $\mathrm{L}_{\text {. }} \mathrm{TiO}_{2}$ (B) Nanoribbons as Negative Electrode Material for Lithium Ion Batteries with High Rate Performance. Inorg. Chem. 2010, 49, 8457-8464.

(34) Moitzheim, S.; Gendt, S. D.; Vereecken, P. M. Investigation of the Li-Ion Insertion Mechanism for Amorphous and Anatase $\mathrm{TiO}_{2}$ Thin-Films. J. Electrochem. Soc. 2019, 166, A1-A9.

(35) Borghols, W. J. H.; Lützenkirchen-Hecht, D.; Haake, U.; Chan, W.; Lafont, U.; Kelder, E. M.; Eck, E. R. H. van; Kentgens, A. P. M.; Mulder, F. M.; Wagemaker, M. Lithium Storage in Amorphous $\mathrm{TiO}_{2}$ Nanoparticles. J. Electrochem. Soc. 2010, 157, A582-A588. 
(36) Auer, A.; Kunze-Liebhäuser, J. Recent Progress in Understanding Ion Storage in SelfOrganized Anodic $\mathrm{TiO}_{2}$ Nanotubes. Small Methods 2018, 0, 1800385.

(37) Deng, C.; Lau, M. L.; Ma, C.; Skinner, P.; Liu, Y.; Xu, W.; Zhou, H.; Zhang, X.; Wu, D.; Yin, Y.; et al. A Mechanistic Study of Mesoporous $\mathrm{TiO}_{2}$ Nanoparticle Negative Electrode Materials with Varying Crystallinity for Lithium Ion Batteries. J. Mater.

Chem. A 2020, 8, 3333-3343.

(38) Zhu, G.-N.; Wang, Y.-G.; Xia, Y.-Y. Ti-Based Compounds as Anode Materials for LiIon Batteries. Energy Environ. Sci. 2012, 5, 6652-6667.

(39) Yan, X.; Wang, Z.; He, M.; Hou, Z.; Xia, T.; Liu, G.; Chen, X. TiO 2 Nanomaterials as Anode Materials for Lithium-Ion Rechargeable Batteries. Energy Technol. 2015, 3, 801814.

(40) Lu, J.; Chen, Z.; Pan, F.; Cui, Y.; Amine, K. High-Performance Anode Materials for Rechargeable Lithium-Ion Batteries. Electrochem. Energy Rev. 2018, 1, 35-53.

(41) Madian, M.; Eychmüller, A.; Giebeler, L. Current Advances in $\mathrm{TiO}_{2}$-Based Nanostructure Electrodes for High Performance Lithium Ion Batteries. Batteries 2018, 4, 7.

(42) Goriparti, S.; Miele, E.; De Angelis, F.; Di Fabrizio, E.; Proietti Zaccaria, R.; Capiglia, C. Review on Recent Progress of Nanostructured Anode Materials for Li-Ion Batteries. $J$. Power Sources 2014, 257, 421-443.

(43) Wang, L.; Sasaki, T. Titanium Oxide Nanosheets: Graphene Analogues with Versatile Functionalities. Chem. Rev. 2014, 114, 9455-9486.

(44) Jiang, C.; Zhang, J. Nanoengineering Titania for High Rate Lithium Storage: A Review. J. Mater. Sci. Technol. 2013, 29, 97-122.

(45) Li, Y.; Chueh, W. C. Electrochemical and Chemical Insertion for Energy Transformation and Switching. Annu. Rev. Mater. Res. 2018, 48, 137-165.

(46) Augustyn, V.; McDowell, M. T.; Vojvodic, A. Toward an Atomistic Understanding of Solid-State Electrochemical Interfaces for Energy Storage. Joule 2018, 2, 2189-2193.

(47) Yabuuchi, N.; Ohzuku, T. Novel Lithium Insertion Material of $\mathrm{LiCo}_{1 / 3} \mathrm{Ni}_{1 / 3} \mathrm{Mn}_{1 / 3} \mathrm{O}_{2}$ for Advanced Lithium-Ion Batteries. J. Power Sources 2003, 119-121, 171-174.

(48) Shen, K.; Chen, H.; Klaver, F.; Mulder, F. M.; Wagemaker, M. Impact of Particle Size on the Non-Equilibrium Phase Transition of Lithium-Inserted Anatase $\mathrm{TiO}_{2}$. Chem.

Mater. 2014, 26, 1608-1615. 
(49) Dylla, A. G.; Henkelman, G.; Stevenson, K. J. Lithium Insertion in Nanostructured $\mathrm{TiO}_{2}$ (B) Architectures. Acc. Chem. Res. 2013, 46, 1104-1112.

(50) Hu, Y.-S.; Kienle, L.; Guo, Y.-G.; Maier, J. High Lithium Electroactivity of NanometerSized Rutile $\mathrm{TiO}_{2}$. Adv. Mater. 2006, 18, 1421-1426.

(51) Liu, H.; Strobridge, F. C.; Borkiewicz, O. J.; Wiaderek, K. M.; Chapman, K. W.; Chupas, P. J.; Grey, C. P. Capturing Metastable Structures during High-Rate Cycling of $\mathrm{LiFePO}_{4}$ Nanoparticle Electrodes. Science 2014, 344, 1252817.

(52) Zhang, X.; van Hulzen, M.; Singh, D. P.; Brownrigg, A.; Wright, J. P.; van Dijk, N. H.; Wagemaker, M. Rate-Induced Solubility and Suppression of the First-Order Phase Transition in Olivine $\mathrm{LiFePO}_{4}$. Nano Lett. 2014, 14, 2279-2285.

(53) de Klerk, N. J. J.; Vasileiadis, A.; Smith, R. B.; Bazant, M. Z.; Wagemaker, M. Explaining Key Properties of Lithiation in $\mathrm{TiO}_{2}$-Anatase Li-Ion Battery Electrodes Using Phase-Field Modeling. Phys. Rev. Mater. 2017, 1, 025404.

(54) Tang, M.; Carter, W. C.; Chiang, Y. M. Electrochemically Driven Phase Transitions in Insertion Electrodes for Lithium-Ion Batteries: Examples in Lithium Metal Phosphate Olivines. Annu. Rev. Mater. Res. 2010, 40, 501-529.

(55) Bai, P.; Cogswell, D. A.; Bazant, M. Z. Suppression of Phase Separation in $\mathrm{LiFePO}_{4}$ Nanoparticles During Battery Discharge. Nano Lett. 2011, 11, 4890-4896.

(56) Cook, J. B.; Lin, T. C.; Kim, H.-S.; Siordia, A.; Dunn, B. S.; Tolbert, S. H. Suppression of Electrochemically Driven Phase Transitions in Nanostructured $\mathrm{MoS}_{2}$ Pseudocapacitors Probed Using Operando X-Ray Diffraction. ACS Nano 2019.

(57) Singer, A.; Ulvestad, A.; Cho, H.-M.; Kim, J. W.; Maser, J.; Harder, R.; Meng, Y. S.; Shpyrko, O. G. Nonequilibrium Structural Dynamics of Nanoparticles in $\mathrm{LiNi}_{1 / 2} \mathrm{Mn}_{3 / 2} \mathrm{O}_{4}$ Cathode under Operando Conditions. Nano Lett. 2014, 14, 5295-5300.

(58) Wagemaker, M.; Kearley, G. J.; van Well, A. A.; Mutka, H.; Mulder, F. M. Multiple Li Positions inside Oxygen Octahedra in Lithiated $\mathrm{TiO}_{2}$ Anatase. J. Am. Chem. Soc. 2003, $125,840-848$.

(59) Wagemaker, M.; Borghols, W. J. H.; van Eck, E. R. H.; Kentgens, A. P. M.; Kearley, G. J.; Mulder, F. M. The Influence of Size on Phase Morphology and Li-Ion Mobility in Nanosized Lithiated Anatase $\mathrm{TiO}_{2}$. Chem. Weinh. Bergstr. Ger. 2007, 13, 2023-2028.

(60) Wagemaker, M.; van de Krol, R.; Kentgens, A. P. M.; van Well, A. A.; Mulder, F. M. Two Phase Morphology Limits Lithium Diffusion in $\mathrm{TiO}_{2}$ (Anatase): A ${ }^{7} \mathrm{Li}$ MAS NMR Study. J. Am. Chem. Soc. 2001, 123, 11454-11461. 
(61) van de Krol, R.; Goossens, A.; Meulenkamp, E. A. In Situ X-Ray Diffraction of Lithium Intercalation in Nanostructured and Thin Film Anatase $\mathrm{TiO}_{2}$. J. Electrochem. Soc. 1999, $146,3150-3154$.

(62) Lindström, H.; Södergren, S.; Solbrand, A.; Rensmo, H.; Hjelm, J.; Hagfeldt, A.; Lindquist, S.-E. $\mathrm{Li}^{+}$Ion Insertion in $\mathrm{TiO}_{2}$ (Anatase). 1. Chronoamperometry on CVD Films and Nanoporous Films. J. Phys. Chem. B 1997, 101, 7710-7716.

(63) Sussman, M. J.; Yasin, A.; Demopoulos, G. P. On the Complex Interplay of Crystallinity and Surface Area Effects on Li-Ion Intercalation and Pseudocapacitive Storage Properties of Nanocrystalline Anatase. J. Power Sources 2014, 272, 58-67.

(64) Wagemaker, M.; Mulder, F. M. Properties and Promises of Nanosized Insertion Materials for Li-Ion Batteries. Acc. Chem. Res. 2012, 46, 1206-1215.

(65) Augustyn, V.; Simon, P.; Dunn, B. Pseudocapacitive Oxide Materials for High-Rate Electrochemical Energy Storage. Energy Environ. Sci. 2014, 7, 1597.

(66) Wang, J.; Polleux, J.; Lim, J.; Dunn, B. Pseudocapacitive Contributions to Electrochemical Energy Storage in $\mathrm{TiO}_{2}$ (Anatase) Nanoparticles. J. Phys. Chem. C 2007, 111, 14925-14931.

(67) Shin, J.-Y.; Samuelis, D.; Maier, J. Sustained Lithium-Storage Performance of Hierarchical, Nanoporous Anatase $\mathrm{TiO}_{2}$ at High Rates: Emphasis on Interfacial Storage Phenomena. Adv. Funct. Mater. 2011, 21, 3464-3472.

(68) Lu, J.; Chen, Z.; Ma, Z.; Pan, F.; Curtiss, L. A.; Amine, K. The Role of Nanotechnology in the Development of Battery Materials for Electric Vehicles. Nat. Nanotechnol. 2016, $11,1031-1038$.

(69) Murray, C. B.; Kagan, C. R.; Bawendi, M. G. Synthesis and Characterization of Monodisperse Nanocrystals and Close-Packed Nanocrystal Assemblies. Annu. Rev. Mater. Sci. 2000, 30, 545-610.

(70) Yin, Y.; Alivisatos, A. P. Colloidal Nanocrystal Synthesis and the Organic-Inorganic Interface. Nature 2005, 437, 664-670.

(71) Liu, G.; Yang, H. G.; Pan, J.; Yang, Y. Q.; Lu, G. Q. M.; Cheng, H.-M. Titanium Dioxide Crystals with Tailored Facets. Chem. Rev. 2014, 114, 9559-9612.

(72) Cargnello, M.; Gordon, T. R.; Murray, C. B. Solution-Phase Synthesis of Titanium Dioxide Nanoparticles and Nanocrystals. Chem. Rev. 2014, 114, 9319-9345.

(73) Boles, M. A.; Ling, D.; Hyeon, T.; Talapin, D. V. The Surface Science of Nanocrystals. Nat. Mater. 2016, 15, 141-153. 
(74) Zarghami, M. H.; Liu, Y.; Gibbs, M.; Gebremichael, E.; Webster, C.; Law, M. P-Type $\mathrm{PbSe}$ and PbS Quantum Dot Solids Prepared with Short-Chain Acids and Diacids. ACS Nano 2010, 4, 2475-2485.

(75) Dong, A.; Ye, X.; Chen, J.; Kang, Y.; Gordon, T.; Kikkawa, J. M.; Murray, C. B. A Generalized Ligand-Exchange Strategy Enabling Sequential Surface Functionalization of Colloidal Nanocrystals. J. Am. Chem. Soc. 2011, 133, 998-1006.

(76) Rosen, E. L.; Buonsanti, R.; Llordés, A.; Sawvel, A. M.; Milliron, D. J.; Helms, B. A. Exceptionally Mild Reactive Stripping of Native Ligands from Nanocrystal Surfaces by Using Meerwein's Salt. Angew. Chem. Int. Ed. 2011, 51, 684-689.

(77) Oszajca, M. F.; Bodnarchuk, M. I.; Kovalenko, M. V. Precisely Engineered Colloidal Nanoparticles and Nanocrystals for Li-Ion and Na-Ion Batteries: Model Systems or Practical Solutions? Chem. Mater. 2014, 26, 5422-5432.

(78) Palacin, M. R.; Simon, P.; Tarascon, J. M. Nanomaterials for Electrochemical Energy Storage: The Good and the Bad. Acta Chim. Slov. 2016, 63, 417-423.

(79) Zhang, Q.; Uchaker, E.; L. Candelaria, S.; Cao, G. Nanomaterials for Energy Conversion and Storage. Chem. Soc. Rev. 2013, 42, 3127-3171.

(80) Kim, C.; Buonsanti, R.; Yaylian, R.; Milliron, D. J.; Cabana, J. Carbon-Free $\mathrm{TiO}_{2} \mathrm{Battery}$ Electrodes Enabled by Morphological Control at the Nanoscale. Adv. Energy Mater. 2013, 3, 1286-1291.

(81) Alexander, C. T.; Kim, C.; Yaylian, R.; Cabana, J. Toward General Rules for the Design of Battery Electrodes Based on Titanium Oxides and Free of Conductive Additives. Energy Technol. 2014, 2, 383-390.

(82) Dahlman, C. J.; Agrawal, A.; Staller, C. M.; Adair, J.; Milliron, D. J. Anisotropic Origins of Localized Surface Plasmon Resonance in N-Type Anatase $\mathrm{TiO}_{2}$ Nanocrystals. Chem. Mater. 2019, 31, 502-511.

(83) De Angelis, F.; Di Valentin, C.; Fantacci, S.; Vittadini, A.; Selloni, A. Theoretical Studies on Anatase and Less Common $\mathrm{TiO}_{2}$ Phases: Bulk, Surfaces, and Nanomaterials. Chem. Rev. 2014, 114, 9708-9753.

(84) Morgan, B. J.; Watson, G. W. GGA+U Description of Lithium Intercalation into Anatase $\mathrm{TiO}_{2}$. Phys. Rev. B 2010, 82, 144119.

(85) Boschloo, G.; Fitzmaurice, D. Electron Accumulation in Nanostructured $\mathrm{TiO}_{2}$ (Anatase) Electrodes. J. Phys. Chem. B 1999, 103, 7860-7868. 
(86) van de Krol, R.; Goossens, A.; Meulenkamp, E. A. Electrical and Optical Properties of $\mathrm{TiO}_{2}$ in Accumulation and of Lithium Titanate $\mathrm{Li}_{0.5} \mathrm{TiO}_{2}$. J. Appl. Phys. 2001, 90, 22352242.

(87) Dahlman, C. J.; Tan, Y.; Marcus, M. A.; Milliron, D. J. Spectroelectrochemical Signatures of Capacitive Charging and Ion Insertion in Doped Anatase Titania Nanocrystals. J. Am. Chem. Soc. 2015, 137, 9160-9166.

(88) Harris, S. J.; Timmons, A.; Baker, D. R.; Monroe, C. Direct in Situ Measurements of Li Transport in Li-Ion Battery Negative Electrodes. Chem. Phys. Lett. 2010, 485, 265-274.

(89) Mandal, J.; Du, S.; Dontigny, M.; Zaghib, K.; Yu, N.; Yang, Y. Li ${ }_{4} \mathrm{Ti}_{5} \mathrm{O}_{12}$ : A Visible-toInfrared Broadband Electrochromic Material for Optical and Thermal Management. Adv. Funct. Mater. 2018, 28, 1802180.

(90) Furutsuki, S.; Chung, S.-C.; Nishimura, S.; Kudo, Y.; Yamashita, K.; Yamada, A. Electrochromism of $\mathrm{Li}_{x} \mathrm{FePO}_{4}$ Induced by Intervalence Charge Transfer Transition. $J$. Phys. Chem. C 2012, 116, 15259-15264.

(91) Švegl, F.; Orel, B.; Kaučič, V. Electrochromic Properties of Lithiated Co-Oxide $\left(\mathrm{Li}_{\mathrm{x}} \mathrm{CoO}_{2}\right)$ and Ni-Oxide $\left(\mathrm{Li}_{\mathrm{x}} \mathrm{NiO}_{2}\right)$ Thin Films Prepared by the Sol-Gel Route. Sol. Energy 2000, 68, 523-540.

(92) Fu, Z.-W.; Kong, J.-J.; Qin, Q.-Z. Electrochemical and Electrochromic Properties of Niobium Oxide Thin Films Fabricated by Pulsed Laser Deposition. J. Electrochem. Soc. 1999, 146, 3914-3918.

(93) Zhang, H.; Banfield, J. F. Structural Characteristics and Mechanical and Thermodynamic Properties of Nanocrystalline $\mathrm{TiO}_{2}$. Chem. Rev. 2014, 114, 9613-9644.

(94) Lazzeri, M.; Vittadini, A.; Selloni, A. Structure and Energetics of Stoichiometric $\mathrm{TiO}_{2}$ Anatase Surfaces. Phys. Rev. B 2001, 63, 155409.

(95) Longoni, G.; Pena Cabrera, R. L.; Polizzi, S.; D’Arienzo, M.; Mari, C. M.; Cui, Y.; Ruffo, R. Shape-Controlled $\mathrm{TiO}_{2}$ Nanocrystals for Na-Ion Battery Electrodes: The Role of Different Exposed Crystal Facets on the Electrochemical Properties. Nano Lett. 2017, $17,992-1000$.

(96) Dinh, C.-T.; Nguyen, T.-D.; Kleitz, F.; Do, T.-O. Shape-Controlled Synthesis of Highly Crystalline Titania Nanocrystals. ACS Nano 2009, 3, 3737-3743.

(97) Cho, S. H.; Ghosh, S.; Berkson, Z. J.; Hachtel, J. A.; Shi, J.; Zhao, X.; Reimnitz, L. C.; Dahlman, C. J.; Ho, Y.; Yang, A.; et al. Syntheses of Colloidal F: $\mathrm{In}_{2} \mathrm{O}_{3}$ Cubes: FluorineInduced Faceting and Infrared Plasmonic Response. Chem. Mater. 2019, 31, 2661-2676. 
(98) Gordon, T. R.; Cargnello, M.; Paik, T.; Mangolini, F.; Weber, R. T.; Fornasiero, P.;

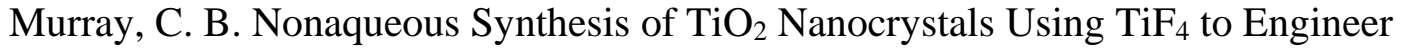
Morphology, Oxygen Vacancy Concentration, and Photocatalytic Activity. J. Am. Chem. Soc. 2012, 134, 6751-6761.

(99) Agrawal, A.; Cho, S. H.; Zandi, O.; Ghosh, S.; Johns, R. W.; Milliron, D. J. Localized Surface Plasmon Resonance in Semiconductor Nanocrystals. Chem. Rev. 2018, 118, 3121-3207.

(100) Llordes, A.; Garcia, G.; Gazquez, J.; Milliron, D. J. Tunable Near-Infrared and VisibleLight Transmittance in Nanocrystal-in-Glass Composites. Nature 2013, 500, 323-326.

(101) Wang, Y.; Runnerstrom, E. L.; Milliron, D. J. Switchable Materials for Smart Windows. Annu. Rev. Chem. Biomol. Eng. 2016, 7, 283-304.

(102) Borghols, W. J. H.; Lützenkirchen-Hecht, D.; Haake, U.; van Eck, E. R. H.; Mulder, F. M.; Wagemaker, M. The Electronic Structure and Ionic Diffusion of Nanoscale $\mathrm{LiTiO}_{2}$ Anatase. Phys. Chem. Chem. Phys. 2009, 11, 5742-5748.

(103) Zhu, Y.; Wang, C. Galvanostatic Intermittent Titration Technique for PhaseTransformation Electrodes. J. Phys. Chem. C 2010, 114, 2830-2841.

(104) Sasaki, T. Memory Effect in a Lithium-Ion Battery. Nat. Mater. 2013, 12, 569-575.

(105) Ventosa, E.; Löffler, T.; Mantia, F. L.; Schuhmann, W. Understanding Memory Effects in Li-Ion Batteries: Evidence of a Kinetic Origin in $\mathrm{TiO}_{2}$ upon Hydrogen Annealing. Chem. Commun. 2016, 52, 11524-11526.

(106) Madej, E.; Mantia, F. L.; Schuhmann, W.; Ventosa, E. Impact of the Specific Surface Area on the Memory Effect in Li-Ion Batteries: The Case of Anatase $\mathrm{TiO}_{2}$. Adv. Energy Mater. 2014, 4, 1400829.

(107) Richter, J.; Henningsson, A.; Karlsson, P.; Andersson, M.; Uvdal, P.; Siegbahn, H.; Sandell, A. Electronic Structure of Lithium-Doped Anatase $\mathrm{TiO}_{2}$ Prepared in Ultrahigh Vacuum. Phys. Rev. B 2005, 71, 235418.

(108) Olson, C. L.; Nelson, J.; Islam, M. S. Defect Chemistry, Surface Structures, and Lithium Insertion in Anatase $\mathrm{TiO}_{2}$. J. Phys. Chem. B 2006, 110, 9995-10001.

(109) Morgan, B. J.; Watson, G. W. Role of Lithium Ordering in the $\mathrm{Li}_{\mathrm{x}} \mathrm{TiO}_{2}$ Anatase $\rightarrow$ Titanate Phase Transition. J. Phys. Chem. Lett. 2011, 2, 1657-1661.

(110) Kang, J. W.; Kim, D. H.; Mathew, V.; Lim, J. S.; Gim, J. H.; Kim, J. Particle Size Effect of Anatase $\mathrm{TiO}_{2}$ Nanocrystals for Lithium-Ion Batteries. J. Electrochem. Soc. 2010, 158, A59. 
(111) Madej, E.; Klink, S.; Schuhmann, W.; Ventosa, E.; La Mantia, F. Effect of the Specific Surface Area on Thermodynamic and Kinetic Properties of Nanoparticle Anatase $\mathrm{TiO}_{2}$ in Lithium-Ion Batteries. J. Power Sources 2015, 297, 140-148.

(112) Meethong, N.; Huang, H.-Y. S.; Carter, W. C.; Chiang, Y.-M. Size-Dependent Lithium Miscibility Gap in Nanoscale $\mathrm{Li}_{1-\mathrm{x}} \mathrm{FePO}_{4}$. Electrochem. Solid-State Lett. 2007, 10, A134A138.

(113) Okubo, M.; Hosono, E.; Kim, J.; Enomoto, M.; Kojima, N.; Kudo, T.; Zhou, H.; Honma, I. Nanosize Effect on High-Rate Li-Ion Intercalation in $\mathrm{LiCoO}_{2}$ Electrode. J. Am. Chem. Soc. 2007, 129, 7444-7452.

(114) Qian, D.; Hinuma, Y.; Chen, H.; Du, L.-S.; Carroll, K. J.; Ceder, G.; Grey, C. P.; Meng, Y. S. Electronic Spin Transition in Nanosize Stoichiometric Lithium Cobalt Oxide. $J$. Am. Chem. Soc. 2012, 134, 6096-6099.

(115) Van der Ven, A.; Wagemaker, M. Effect of Surface Energies and Nano-Particle Size Distribution on Open Circuit Voltage of Li-Electrodes. Electrochem. Commun. 2009, 11, 881-884.

(116) Vittadini, A.; Selloni, A.; Rotzinger, F. P.; Grätzel, M. Structure and Energetics of Water Adsorbed at $\mathrm{TiO}_{2}$ Anatase (101) and (001) Surfaces. Phys. Rev. Lett. 1998, 81, 29542957.

(117) Hummer, D. R.; Kubicki, J. D.; Kent, P. R. C.; Post, J. E.; Heaney, P. J. Origin of Nanoscale Phase Stability Reversals in Titanium Oxide Polymorphs. J. Phys. Chem. C 2009, 113, 4240-4245.

(118) Barnard, A. S.; Zapol, P. Effects of Particle Morphology and Surface Hydrogenation on the Phase Stability of $\mathrm{TiO}_{2}$. Phys. Rev. B 2004, 70, 235403.

(119) da Silva, A. L.; Hotza, D.; Castro, R. H. R. Surface Energy Effects on the Stability of Anatase and Rutile Nanocrystals: A Predictive Diagram for $\mathrm{Nb}_{2} \mathrm{O}_{5}$-Doped- $\mathrm{TiO}_{2}$. Appl. Surf. Sci. 2017, 393, 103-109.

(120) Castro, R. H. R.; Wang, B. The Hidden Effect of Interface Energies in the Polymorphic Stability of Nanocrystalline Titanium Dioxide. J. Am. Ceram. Soc. 2011, 94, 918-924.

(121) Naicker, P. K.; Cummings, P. T.; Zhang, H.; Banfield, J. F. Characterization of Titanium Dioxide Nanoparticles Using Molecular Dynamics Simulations. J. Phys. Chem. B 2005, $109,15243-15249$.

(122) Morgan, B. J.; Carrasco, J.; Teobaldi, G. Variation in Surface Energy and Reduction Drive of a Metal Oxide Lithium-Ion Anode with Stoichiometry: A DFT Study of Lithium Titanate Spinel Surfaces. J. Mater. Chem. A 2016, 4, 17180-17192. 
(123) Cogswell, D. A.; Bazant, M. Z. Theory of Coherent Nucleation in Phase-Separating Nanoparticles. Nano Lett. 2013, 13, 3036-3041.

(124) Xiang, K.; Yang, K.; Carter, W. C.; Tang, M.; Chiang, Y.-M. Mesoscopic Phase Transition Kinetics in Secondary Particles of Electrode-Active Materials in Lithium-Ion Batteries. Chem. Mater. 2018, 30, 4216-4225.

(125) Belak, A. A.; Wang, Y.; Van der Ven, A. Kinetics of Anatase Electrodes: The Role of Ordering, Anisotropy, and Shape Memory Effects. Chem. Mater. 2012, 24, 2894-2898.

(126) Li, Y.; El Gabaly, F.; Ferguson, T. R.; Smith, R. B.; Bartelt, N. C.; Sugar, J. D.; Fenton, K. R.; Cogswell, D. A.; Kilcoyne, A. L. D.; Tyliszczak, T.; et al. Current-Induced Transition from Particle-by-Particle to Concurrent Intercalation in Phase-Separating Battery Electrodes. Nat. Mater. 2014, 13, 1149-1156.

(127) Delmas, C.; Maccario, M.; Croguennec, L.; Le Cras, F.; Weill, F. Lithium Deintercalation in $\mathrm{LiFePO}_{4}$ Nanoparticles via a Domino-Cascade Model. Nat. Mater. 2008, 7, 665-671.

(128) Ferguson, T. R.; Bazant, M. Z. Phase Transformation Dynamics in Porous Battery Electrodes. Electrochim. Acta 2014, 146, 89-97.

(129) Dreyer, W.; Jamnik, J.; Guhlke, C.; Huth, R.; Moškon, J.; Gaberšček, M. The Thermodynamic Origin of Hysteresis in Insertion Batteries. Nat. Mater. 2010, 9, 448453.

(130) Meethong, N.; Kao, Y.-H.; Carter, W. C.; Chiang, Y.-M. Comparative Study of Lithium Transport Kinetics in Olivine Cathodes for Li-Ion Batteries. Chem. Mater. 2010, 22, 1088-1097.

(131) Allen, J. L.; Jow, T. R.; Wolfenstine, J. Kinetic Study of the Electrochemical FePO 4 to $\mathrm{LiFePO}_{4}$ Phase Transition. Chem. Mater. 2007, 19, 2108-2111.

(132) Humphreys, F. J.; Hatherly, M. Recrystallization and Related Annealing Phenomena, 2nd ed.; Elsevier: New York, 2004.

(133) Garcia, G.; Buonsanti, R.; Runnerstrom, E. L.; Mendelsberg, R. J.; Llordés, A.; Anders, A.; Richardson, T. J.; Milliron, D. J. Dynamically Modulating the Surface Plasmon Resonance of Doped Semiconductor Nanocrystals. Nano Lett. 2011, 11, 4415-4420.

(134) Kavan, L.; Grätzel, M.; Gilbert, S. E.; Klemenz, C.; Scheel, H. J. Electrochemical and Photoelectrochemical Investigation of Single-Crystal Anatase. J. Am. Chem. Soc. 1996, 118, 6716-6723. 
(135) Hengerer, R.; Kavan, L.; Krtil, P.; Grätzel, M. Orientation Dependence of ChargeTransfer Processes on $\mathrm{TiO}_{2}$ (Anatase) Single Crystals. J. Electrochem. Soc. 2000, 147, $1467-1472$.

(136) Kavan, L.; Rathouský, J.; Grätzel, M.; Shklover, V.; Zukal, A. Surfactant-Templated $\mathrm{TiO}_{2}$ (Anatase): Characteristic Features of Lithium Insertion Electrochemistry in Organized Nanostructures. J. Phys. Chem. B 2000, 104, 12012-12020.

(137) Shin, J.-Y.; Joo, J. H.; Samuelis, D.; Maier, J. Oxygen-Deficient $\mathrm{TiO}_{2-\delta}$ Nanoparticles via Hydrogen Reduction for High Rate Capability Lithium Batteries. Chem. Mater. 2012, $24,543-551$.

(138) Li, D.; Sun, Y.; Liu, X.; Peng, R.; Zhou, H. Doping-Induced Memory Effect in Li-Ion Batteries: The Case of Al-Doped $\mathrm{Li}_{4} \mathrm{Ti}_{5} \mathrm{O}_{12}$. Chem. Sci. 2015, 6, 4066-4070. 